\title{
Optimal policy identification: Insights from the German electricity market
}

\author{
by Johannes Karl Herrmann and Ivan Savin
}

No. 87 | MARCH 2016

\section{WORKING PAPER SERIES IN ECONOMICS}

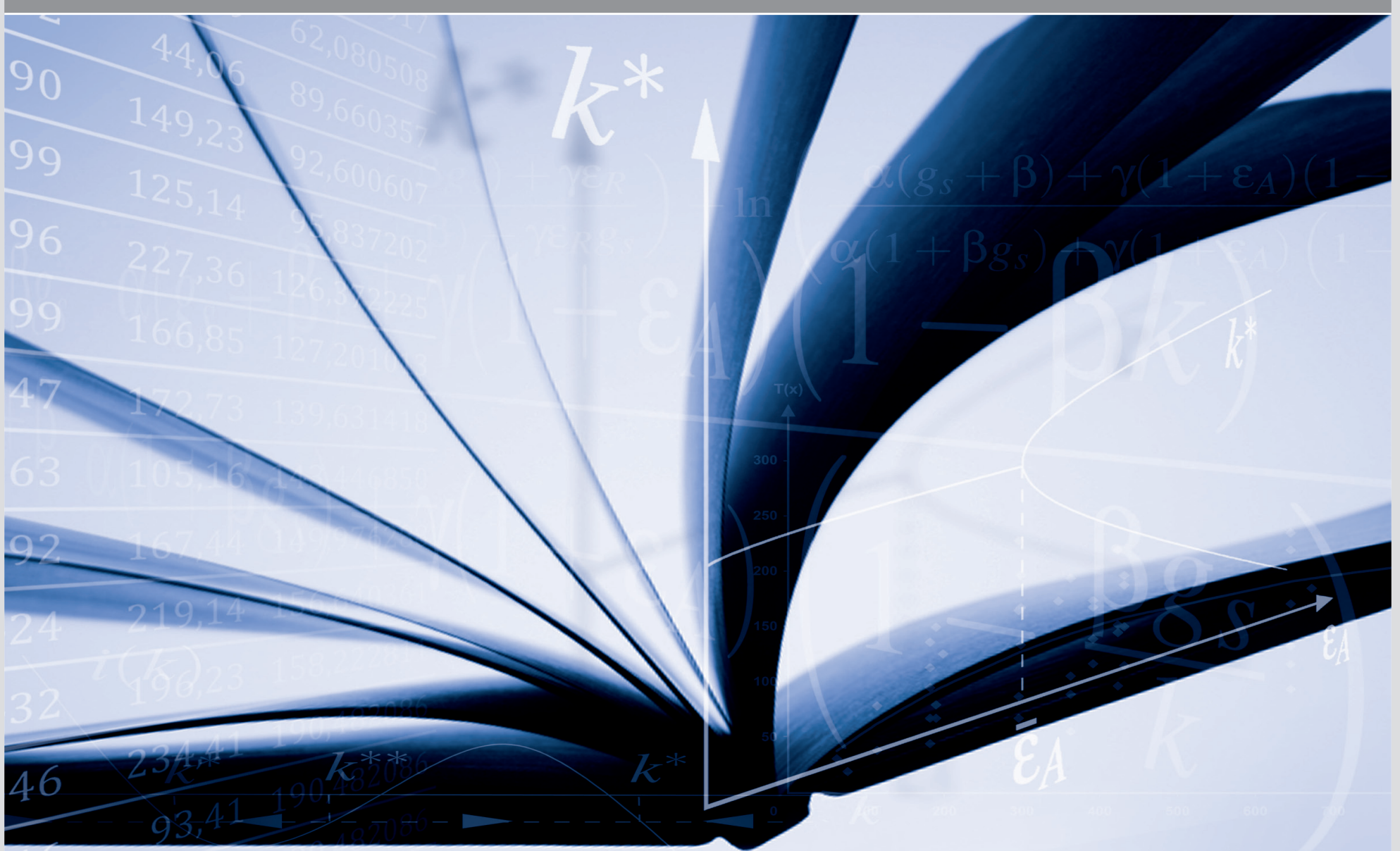




\section{Impressum}

Karlsruher Institut für Technologie (KIT)

Fakultät für Wirtschaftswissenschaften

Institut für Volkswirtschaftslehre (ECON)

Schlossbezirk 12

76131 Karlsruhe

KIT - Die Forschungsuniversität in der Helmholtz-Gemeinschaft

Working Paper Series in Economics

No. 87, March 2016

ISSN 2190-9806

econpapers.wiwi.kit.edu 


\title{
Optimal Policy Identification: Insights from the German Electricity Market*
}

\author{
J. K. Herrmann ${ }^{\dagger \ddagger}$ and I. Savin ${ }^{\dagger \S}$
}

\begin{abstract}
The diffusion of renewable electricity generating technologies is widely considered as crucial for establishing a sustainable energy system in the future. However, the required transition is unlikely to be achieved by market forces alone. For this reason, many countries implement various policy instruments to support this process, also by re-distributing related costs among all electricity consumers. This paper presents a novel history-friendly agent-based study aiming to explore the efficiency of different mixes of policy instruments by means of a Differential Evolution algorithm. Special emphasis of the model is devoted to the possibility of small scale renewable electricity generation, but also to the storage of this electricity using small scale facilities being actively developed over the last decade. Both combined pose an important instrument for electricity consumers to achieve partial or full autarky from the electricity grid, particularly after accounting for decreasing costs and increasing efficiency of both due to continuous innovation. Among other things, we find that the historical policy mix of Germany introduced too strong and inflexible demand-side instruments (like feed-in tariff) too early, thereby creating strong path-dependency for future policy makers and reducing their ability to react to technological but also economic shocks without further increases of the budget.
\end{abstract}

Keywords: differential evolution; electricity storage; energy grid; feed-in tariff; renewable energy

JEL Classification: C63, Q41, Q42, Q48

*Both authors acknowledge financial support from the German Science Foundation (DFG RTG 1411). JKH acknowledges support from the GRETCHEN-Project funded by the German Ministry of Education and Research (BMBF Econ-C-026). IS also acknowledges support from the Helmholtz Association (HIRG-0069) and Projex CSES, Initiative d'Excellence, Université de Strasbourg. Thanks are due to very helpful comments and suggestions from Zakaria Babutsidze, Uwe Cantner and Holger Graf. This work has benefited from presentations at workshops in Turin, Nice, Bielefeld and Klagenfurt as well as at the 15th International Schumpeter Society Conference in Jena and the Annual Congress of the German Economic Association in Muenster.

${ }^{\dagger}$ Friedrich Schiller University of Jena, Faculty of Economics and Business Administration, Germany

${ }^{\ddagger}$ Corresponding author, Bachstrasse 18k Room 224, D-07743 Jena, Germany. Tel.: +49-3641-943207, Fax: +49-3641-943202, johannes.herrmann@uni-jena.de

${ }^{\S}$ Chair for Economic Policy, Karlsruhe Institute of Technology, Germany and Bureau d'Economie Théorique et Appliquée, UMR 7522 Université de Strasbourg - CNRS, France 


\section{Introduction}

"there must be a "sweet spot" in [...] subsidy design space at which subsidies are maximally effective in triggering adoption and widespread diffusion without wasting money on adopters who would have adopted anyway'

(Cantono and Silverberg, 2009, p. 495)

The diffusion of renewable electricity generating technologies (REGT) is widely seen as a crucial part for establishing a sustainable energy system in the future.1 However, the current energy system is designed for and locked into the usage of fossil fuels, so that the required transition is unlikely to be achieved by market forces alone. For this reason, many countries have recently implemented different policy instruments to support innovation in and diffusion of REGT (e.g., Grau et al., 2012). Most instruments try to foster an innovative activity in REGT by lowering R\&D costs for private companies or by performing $R \& D$ in public research institutes (del Río and Bleda, 2012); or directly support their diffusion via subsidies. The main goal of these policies is to make REGT competitive (in terms of costs) with fossil fuels inside the electricity grid.

In this diffusion-oriented context, a specific feature of the electricity from REGT gains importance, namely the possibility of small scale electricity generation without the need of further inputs. Combined with the possibility of energy storage, this can be used by electricity consumers to become electricity producers themselves (partial autarky) or even to achieve full autarky from the electricity grid in the sense that the consumer can generate and store as much or even more electricity than she consumes in a normal period (Zahedi, 2006). This becomes particularly important as with the decreasing costs and increasing efficiency of both, storage and REGT, the necessary investments required to become an electricity producer, and to become fully autarkic from the electricity grid, fall. The latter can be considered as an unintended side effect of the original policy measures and is a paradigm change in the electricity generation systems of developed countries, which were built around large, fossil electricity generating plants that distributed an electricity through complex electricity grids $2^{2}$ REGT and storage together provide the possibility of an individual electricity supply, which is also environmentally-friendly.

Another incentive to invest into REGT comes from re-distribution of costs of the electricity generated from more expansive renewable sources to cheaper fossil fuels (e.g., Bode and Groscurth, 2006), which raises the consumption price one has to pay for electricity from the grid. By becoming electricity producers themselves, consumers avoid the extra costs and hedge against rising prices in the future. Once more consumers become fully autarkic (and do not demand electricity from the grid), the costs for consumers remaining in the grid increase (since the costs are distributed among fewer people), creating the possibility of a snowball effect. This puts the stability of the grid in question, forcing the policy makers either to change their policy or risk a collapse of the grid.

In this paper we aim to compare possible policy instruments and find the optimal combination, which stimulates consumers to invest into REGT and even to become au-

\footnotetext{
${ }^{1}$ The intended transition from fossil to renewable sources does not have to be seen solely from the view of possible shortage of fossils, but also as a decision to 'establish new pathways, [...] which may offer richer opportunities for economic growth or prosperity' (Steinmueller, 2013).

${ }^{2}$ More details on the visionary perspective of the future electricity market one can find in Rifkin (2011) describing the 'five pillars of the Third Industrial Revolution'.
} 
tarkic from the grid (and how fast this occurs). Thus, policy instruments are compared in terms of REGT electricity diffusion and stability of the electricity grid $3^{3}$

Since the transition is an out-of-equilibrium-process (Arthur, 2006), we utilise evolutionary modeling approach (see Safarzynska et al., 2012 for a review) and build a novel agent-based simulation model (ABM). We find ABM better fitting our research problem in comparison to more traditional techniques (like DSGE models) because we avoid presuming unrealistic cognitive capabilities of our agents (De Grauwe, 2011), given the uncertainty related to constantly changing prices of fossil and REGT electricity but also unforeseeable stochastic events (e.g., emergence of the small scale storage technology). Furthermore, we aim to address income inequality and interaction among heterogeneous agents, which would have been incompatible with the traditional representative agent assumption (Fagiolo and Roventini, 2012, p. 84). The latter is particularly important since, as we demonstrate in this paper, the same policy instruments differently affect electricity consumers depending on their income stimulating some of them to install REGT plants and sell electricity to other consumers, thus, fundamentally changing the electricity market and demonstrating emerging properties (the snowball effect aforementioned) out of individual decisions (Battiston et al., 2016). ABMs have gained an increasing interest in different fields of economic research also thanks to the possibility of an extensive and fast simulation analysis for different effects and parameter settings (for a literature review see, e.g., Tesfatsion and Judd, 2006). In the last years, ABMs have become popular to model transitory processes (see, e.g., Nannen and van den Bergh, 2010, Lopolito et al., 2013 and Safarzynska and van den Bergh, 2013) and electricity markets (see, e.g., Sensfußet al., 2007, Weidlich and Veit, 2008 and Guerci et al., 2010 or Ringler et al., 2016 for a recent overview on smart electricity grids). In addition, there is a large body of literature utilizing this approach to investigate the problem of diffusion of eco-innovations (see Cantono and Silverberg, 2009, Bleda and Valente, 2009 and Windrum et al., 2009).

With this ABM, we have two main objectives. The first one is to illustrate in a history-friendly manner (see, e.g., Malerba et al., 2008; Garavaglia, 2010), which policy instruments played a critical role in the electricity market of Germany in the early 1990s in fostering transition towards the use of electricity generated from REGT. Back then, a low number of large fossil power plants supplied the whole economy with electricity, which was transmitted via the electricity grid. From this situation onwards, we show that policy intervention was necessary to start the transition and is still necessary if the transition shall progress further. For that reason, our model accounts for different policy instruments that were implemented in real life.

The second objective is to investigate which possible mix of instruments is likely to deliver the best outcomes (in terms of diffusion reached and grid stability preserved) in the near future $4^{4}$ To identify an optimal policy mix, we apply an exercise from optimal control literature (see, e.g., Blueschke-Nikolaeva et al., 2012), where a set of controls is optimised to achieve policy targets as close as possible. Since the search space of possible solutions is infinite (due to the continuous nature of the problem) and not necessarily 'well-behaved' (with non-linearities and multiple local optima), a Differential Evolution algorithm is used. We compare different mixes of instruments with respect to how steady the transition

\footnotetext{
${ }^{3}$ In the literature there is no universal definition of circumstances, under which grid may break down, and for simplicity we penalize the percentage of unstably produced electricity over time.

${ }^{4}$ Alternatively, the model could be relatively easily adjusted to compromise also along the third dimension, which is policy budget applied, but for this one must declare how to weight cost and benefit of the policy. We leave this extension for further research.
} 
progresses are and how much REGT technologies are diffused. We purposely underline importance of grid stability, as unstable electricity supply has several adverse effects. The most obvious is the risk of blackouts, which hinder production processes and displeases people used to steady electricity supply (as it is the case in most industrialised countries) $!^{5}$

The rest of the paper is organised as follows. In Section 2 we present the basic model together with a description of policy intervention mechanisms applied in Germany. In Section 3 we address the parameter calibration issues of the present ABM, compare its evolution over the 'history-friendly' period with empirical findings and stress stylized facts observed. Section 4 presents a counterfactual analysis, where by means of the Differential Evolution algorithm we identify optimal policy mixes for different time periods. Section 5 discusses the implications of the present study and concludes.

\section{Model}

This section presents a model meant to serve a consistent but concise representation of routines, relationships and behaviour of economic agents as indicated in available literature. We try to balance between following appreciative theorising making our model empirically oriented and implementing mechanisms closely reconstructing some real world processes (such as merit-order pricing), but keeping our model simple and well-suited for logical explorations helping to understand what factors make the model behave as it does.

In this ABM, two connected markets, the one for electricity and the one for electricity generation equipment, are modeled (Figure 1). These markets are populated with three different types of actors, namely electricity consumers, fossil electricity producer and equipment manufacturers. Two technologies for electricity generation are available, fossil fuels and REGT. The heterogeneity inside both technologies (i.e., nuclear, coal and gas for fossil on the one hand, and wind and solar energy on the other hand) is ignored deliberately to reduce complexity. Note that under REGT technologies we solely understand those new technologies that have been experiencing an immense rise in the last two decades providing renewable but unstable energy supply. For that reason, we concentrate on wind and photovoltaic leaving hydro-power and biomass outside the scope of REGT, assuming the latter two being a part of the fossil (stable and established) technology ${ }^{6}$

The model is run for $T$ periods (months), where $T$ has a maximum of 360. For the first twenty years then we apply policy interventions in a history-friendly manner as it was done in Germany in 1990-2010, which is described in more detail in Section 3 . For the last ten years, we aim to identify an optimal mix of policy interventions matching best the policy target to reach $26 \%$ diffusion of REGT by 2020 - policy target formulated by German Federal Government (2010).7 In addition, we compare different policy mixes for the period of 30 years to see, whether one could reach better state of the world having started alternative policy strategies earlier.

\footnotetext{
${ }^{5}$ Also, unstable electricity supply decreases power quality, which might damage electrical devices (see e.g. Farhoodnea et al. (2013) or Liu et al. (2011)).

${ }^{6}$ Hydro-power has long been applied for electricity generation, indicating that the best locations are already in use, limiting the possibility to increase electricity generation from it. Biomass, on the other hand, is limited by the availability of soil to grow the plants needed, which conflicts with the needs to feed an ever increasing human population.

${ }^{7}$ Since the biomass and hydro-power technologies are not considered in the scope of REGT and also can hardly increase their share in the electricity market (in 2010 it was around 8.9\%) in the next decade, we assume that the photovoltaic and wind technologies alone have to contribute in reaching the target of $35 \%$ set by German Government, i.e. increase their share from the current $8.1 \%$ to $26 \%$.
} 


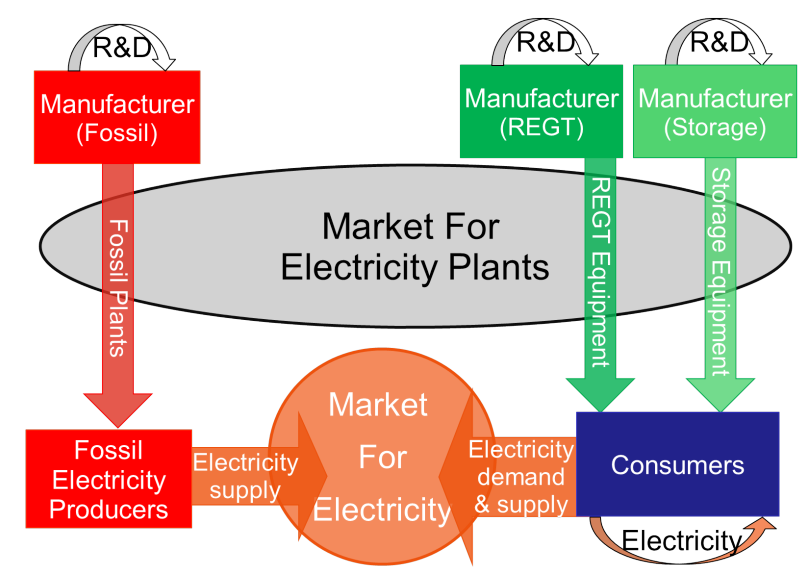

Figure 1: Markets for Electricity and Electricity Generation Equipment

\subsection{Technologies}

In our model only two technologies for electricity generation are assumed, fossil and renewable. Both technologies are embedded in power generation equipment sold by manufacturers. Innovation in one of them increases efficiency or decreases cost of the technology, but cannot introduce new ones. The only exception is the storage technology, which however can only become available by basic research conducted by the state.

Each technology has two independent attributes regarding its cost effectiveness: installation costs and efficiency. Installation costs are the price actors have to pay if they want to install the technology. Here it is assumed that manufacturers produce 'turn-key' installations, so that other actors do not bear additional costs after purchasing the equipment. Installations are fixed in size, but it is possible to install more than one plant at once, if agents possess the sufficient space and budget. Efficiency determines how much electricity can be generated from one plant (electricity yield per size) and can be improved by innovation. Installation cost, on the other hand, can be decreased by learning-curve effects (described in detail in Section 2.3).

The fossil technology is assumed to be mature at the starting point of the simulation. Its efficiency is high and the costs per unit of electricity generated are low. However, due to the maturity of the technology, there is little room for further improvements. Since fossil power plants are big (each one generates a high amount of electricity), their number is small compared to the number of consumers. To operate, they need fuels which have to be acquired every period. 8 The fossil electricity supply is stable, thereby putting no burden on the stability of the electricity grid.

In contrast to the fossil technology, REGT are modeled as new at the starting point of the simulation, resulting in low efficiency and high cost per unit of electricity. REGT plants are small scale of the size that can be installed by majority of households. If a household wants to install more plants (because of, e.g., larger space available), it simply buys more than one plant. REGT do not need additional fuels to run, which means that they can produce at zero marginal costs. However, since there are investment costs that investors aim to earn back, households want to achieve a positive price when selling electricity (Section 2.4.1). An important drawback of electricity generated by REGT is unstable supply, which may put the stability of the electricity grid in question, especially if the share of electricity generated from REGT reaches high levels.

\footnotetext{
${ }^{8}$ The dynamics of the fuel price is described in Section 2.2 .2
} 
Instability of REGT electricity supply is of two types: short term instability resulting in different amount of electricity produced on different days, hours or even minutes, and mid-term instability, where in different periods of year different amount of sunshine and wind is present. While we explicitly model only the latter one, both present a potential threat for the grid stability. To model the mid term instability, there are periodically times when REGT cannot generate electricity at its full potential. This can be seen as a simple way of modeling the dependence of REGT on weather conditions, which change over the year. Thus, since a period in the model represents one month, there is a cyclical pattern with a length of 12 periods, where the electricity generation from each REGT plant changes each period. After 12 periods, the cycle starts anew:

$$
\text { Generation }_{i, t}=\text { MaxGeneration }_{i, t} \times \text { SeasonValue }_{t},
$$

where electricity consumer $i$ can generate in a specific period $t$ a certain amount of electricity at maximum. SeasonValue $t_{t}$ is a value between 0 and 1.9 stating which share of the maximum generation MaxGeneration ${ }_{i, t}$ can be reached in a specific month. Hence, the supply of electricity from REGT is unstable over the year, creating additional demand for fossil plants in some months, while there is excessive supply in other periods.

The storage technology is different from the two others in several aspects. First of all, it is not available from the beginning, but has a chance to be 'discovered' at a later point by basic research. Although it does not generate electricity, it is used to store electricity generated from REGT, thereby transforming it into stable energy supply. However, the investment costs of the storage technology have to be added upon the price of electricity from REGT. There are different promising technologies for electricity storage in development, although most were in an premature state at the end of the history-friendly part of the simulation (for an overview, see Hadjipaschalis et al., 2009). A very comprehensive analysis of most possible storage technologies can be found in EASE/EERA (2013). In our model, we only consider small scale electricity storage solutions, like fuel cells or batteries (an overview of the different battery solutions is provided by Divya and Østergaard (2009)), for two reasons. First, large scale storage solutions (such as pump storage) are not decided upon by the actors of our model, but rather by policy maker, making them exogenous to our model. Second, the construction of large scale storage facilities is likely to induce resistance from the population, as can be observed from the discussion about the construction of new pump storage facilities in Germany, as described in Steffen (2012). Therefore, we consider it unlikely that a high number of new large scale storage facilities will be built in near future. Small scale storage solutions, in contrast, are on the verge of becoming profitable (see Colmenar-Santos et al. 2012 ) and this profitability increases with increasing electricity prices, as shown in Mishra et al. (2012). In addition, their installation is a private decision of households, which is in line with our assumptions about the consumers.

Each investment has a finite life expectancy (see Life $e_{f}$, Life $_{r}$ and Life $e_{s}$ in Table 1 in Appendix A, after which it either has to be replaced at the current investment costs or removed (at zero costs). The life expectancy varies between the different technologies. Fossil power plants, both due to the maturity of the technology and the size of the power plants, are assumed to have a higher life expectancy than REGT and storage plants.

\footnotetext{
${ }^{9}$ The specific values are chosen arbitrarily, since they are only used to generate additional variance: $1,1,0.9,0.9,0.85,0.8,0.8,0.85,0.9,0.95,0.95,1$.
} 


\subsection{Actors}

\subsubsection{Electricity Consumers}

Electricity consumers (represented by households) are central actors of our model. Their number is set to 1000. Consumers are heterogeneous in several dimensions. They have different income levels. The distribution of income is based on the German income deciles in 1991, which are taken from German Council of Economic Experts (2009) 10 Since the data on income contains only ten decile values, we add additional variance by dividing the consumers into ten groups, one for each income decile Decile ${ }_{k}$, where $k=1, . ., 10$, so that 100 consumers share one Decile $e_{k}$. For each group, income is assigned as follows:

$$
\text { Income }_{i, k} \sim \mathcal{N}\left(5 \times \text { Decile }_{k}, 2 \times \text { Decile }_{k}\right) .
$$

Additionally, we restrict the income distribution to prevent very small incomes. This is done to represent governmental aids to poor people and to allow all consumers to have sufficient income to pay for electricity at the beginning.

Other attributes of the consumers are assumed to correlate imperfectly with income, for example, the space available to install REGT. REGT needs sufficient space to be installed, which is assumed to be sparse for most consumers:

$$
\text { Space }_{i}=\text { floor }\left(\frac{\text { Income }_{i}}{10}-3 \times X_{i}\right), \text { where } X \sim \mathcal{N}(2,1),
$$

where Space $_{i}$ denotes the amount of space the consumer $i$ has for installing REGT and $X$ is used to generate additional variance. The floor(.) function (rounding argument downwards) creates non-negative integer values for space distribution (since installation size is one) with a considerable proportion of households with no space available.

Irradiation (electricity yield per space) is additionally used to account for heterogeneity of space in terms of REGT productivity. Solar irradiation in Germany is distributed between 0.7 and 1 (see JRC - European Commission (2015)), while for wind it is between 0 and 1 . The irradiation value for each consumer is drawn from a normal distribution:

$$
\text { Irradiation }_{i} \sim \mathcal{N}(0.6,0.2),
$$

which is additionally restricted in the interval $[0.4,1]$.

Electricity demand is also assumed to be weakly positively correlated with income, as richer consumer can afford higher consumption:

$$
\text { Demand }_{i}=\sqrt{\text { Income }_{i}} \times Y_{i}, \text { where } Y \sim \mathcal{N}(1,0.2) .
$$

The demand for electricity of a consumer stays constant over time. However, if a consumer installs the REGT and storage technologies, she will be able to satisfy at least parts of her own demand by self-production. Therefore, the relevant value is the

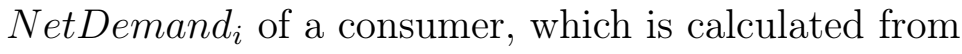

$$
\text { NetDemand }_{i}=\text { Demand }_{i}-\text { SelfConsumption }_{i},
$$

where SelfConsumption $i$ is the amount of electricity a consumer can produce and store.

\footnotetext{
${ }^{10}$ The values for the income deciles are: $4.1,5.8,6.8,7.7,8.5,9.5,10.6,12,14.3,20.7$.
} 
The most important source of heterogeneity among consumers are their preferences. The first preference is for environmental protection, which is bound between 0 and 0.9 . This preference is assumed to be imperfectly correlated with income ${ }^{11}$ so that people with high preferences tend to have a higher income. A rich number of empirical studies has shown that wealthier households are willing to pay higher prices for eco-products (e.g. Roe et al., 2001, Wiser, 2007, Diaz-Rainey and Ashton, 2011). Most consumers have no or only weak preferences for environmental protection. A fraction of consumers (which is a parameter of the simulation and in an default setting equals $5 \%$ ), however, have very high preferences. These consumers are called 'eco-warriors' (e.g., Williams, 2013). The role of those eco-warriors is important since, on the one hand, due to their high willingness to pay, eco-products sustain at least as niche markets, while on the other hand, those households signal to policy makers importance of ecological goods (e.g., by pointing to the rights of future generations) and actively vote for public intervention. For example, in Germany environmental activists played a key role in supporting the feed-in tariff (Lauber and Mez, 2004). The preference values are calculated in the following way:

$$
\text { PrefEP } P_{i}= \begin{cases}\operatorname{Pref}_{i}^{1} \sim \mathcal{N}(0.9,0.1) & \text { if the consumer is an eco-warrior, } \\ \text { Pref } f_{i}^{2} \sim \mathcal{N}(-0.2,0.4) & \text { otherwise }\end{cases}
$$

The values for Pref $f^{1}$ and $P r e f^{2}$ are chosen to ensure values close to 0.9 for eco-warriors and a distribution with many zeros and few intermediate values for other consumers. This represents the situation in Germany at the beginning of 1990s, where environmental issues were already causing concern for many people (e.g., due to the oil crisis), but very few people invested into REGT (see Jacobsson and Lauber, 2006).

The preference for environmental protection lowers the price consumers subjectively perceive altering the decision on which form of electricity to demand (and consequently on whether to invest into REGT). Thus, even if the objective price for REGT electricity is higher, consumers with high preferences may still demand it. As an additional restriction, consumers avoid spending for electricity a share of their income beyond a certain threshold. The actual share that consumers are ready to spend is a parameter of the simulation, $\phi$. In Great Britain, households spending more than $10 \%$ of their income on energy are labeled to live in 'fuel-poverty' (Department of Energy \& Climate Change, 2013), which we use as threshold here. If consumers are in danger to pay a higher share of their income, they also consume the objectively cheapest form of electricity. If consumers demand electricity from REGT, but there is no supply present in the electricity market, consumers may invest into REGT themselves, becoming 'consumer-producers' (on the conditions when a consumer invests in REGT see Section 2.4.2).

Besides preference for environmental protection, there is a preference for autarky. This preference makes the technology more attractive to consumers and starts mattering only after the technology becomes available. It can be interpreted as a preference to consume self-generated electricity because of the fear of rising prices of the grid-based electricity (as the incentive to self-generate and -consume electricity increases with rising electricity prices). If no storage is installed, no self-generated electricity can be consumed by the household, motivating it to make the investment (if together with the storage the REGT electricity is still considered as subjectively cheapest). Once storage capacity is installed, the electricity supply from REGT becomes stable and all self-generated electricity that is

\footnotetext{
${ }^{11}$ Correlation between environmental preferences and income equals 0.1 .
} 
stored can be self-consumed. The extent of the preference is correlated with the electricity demand per income,,${ }^{12}$ as a high level of electricity demand per income increases the effect of changing electricity prices:

$$
\text { Pref Autarky }_{i} \sim \mathcal{N}\left(\frac{\text { Demand }_{i}}{\text { Income }_{i}}-\frac{\sum_{i=1}^{N} \frac{\text { Demand }_{i}}{\text { Income }_{i}}}{N}, 0.3\right) .
$$

Here, PrefAutarky $i$ is calculated from a normal distribution, where the mean of the demand per income is subtracted from the individual value to ensure that a sufficient number of consumers have very small (or zero) preference values, since we assume high preference values for autarky to be an exception. See Figure 12 in Appendix B for illustration of those consumer characteristics described.

\subsubsection{Fossil Electricity Producers}

Producers generate electricity using fossil power plants and sell it to electricity consumers via the electricity grid. For simplicity, each producer operates only one power plant (therefore, the terms fossil producer and fossil power plant used as synonyms). For the same reason, the producers cannot invest into REGT or storage. Producers are profit oriented, which means that they aim to avoid losses from operating their power plants. The central variable that indicates if losses are made is the 'up-time' of a power plant. The up-time is the share of the maximum electricity generation capacity a plant is able to feed-in (hence, up-time is a number $\in[0,1]$ ). A power plant generates losses if the up-time is lower than a certain threshold $\gamma$. This simplified rule ensures that those fossil power plants with lower cost (and in reality making profits) will feed-in most of their supply and stay in the market longer, while those with relatively higher cost, may have to exit the market first. The rule has a convenient feature of not making specific assumptions on how past profits can be accumulated to finance future performance.

The conditions for a power plant to run (to be inside the market) are described in Section 2.4.1. The number of fossil power plants is low compared to the number of consumers. To be precise, the number of fossil producers is hundred times smaller than the number of consumers. The size of power plants is determined at the beginning of the simulation in a way to guarantee that the entire demand is satisfied by the fossil power ${ }^{13}$

The cost of each power plant consists of capital cost and fuel cost:

$$
\text { CostFossil }_{p, t}=\text { CapitalCost }_{p}+\text { FuelCost }_{p, t},
$$

where $p=1, \ldots, P$, with $P$ as the maximum number of fossil producers on the market. The capital cost reflects the income needed to earn back the installation costs:

$$
\text { CapitalCost }_{p}=\frac{\text { InstallCost }_{f, t}}{\text { Life }_{f} \times 12}
$$

where InstallCost $_{f, t}$ denotes the cost of installing a fossil plant. Since the cost is dis-

\footnotetext{
${ }^{12}$ This correlation equals 0.25 in our model.

${ }^{13}$ Note that power plants will not shut down permanently prior to hitting their life expectancy, as there are no maintenance costs if the plant is not running. However, a low up-time will discourage replacement investment once the plant reaches its life expectancy. New power plants have to earn back their investment costs, which is unlikely if the power plant does not sell a sufficient amount of electricity.
} 
tributed over the lifetime of the plant ${ }^{14}$ it is divided by Life $e_{f}$. Also, since electricity is sold on a monthly basis, we also divide it by 12 . The fuel costs are calculated from:

$$
\text { FuelCost }_{p, t}=\text { FuelPrice }_{t} / \text { Efficiency }_{f, t},
$$

where Efficiency $_{f, t}$ denotes the efficiency level of the plant, while FuelPrice $_{t}$ denotes the price of the fossil fuels which have to be acquired every period. Note that, while CapitalCost $_{p}$ and Efficiencyf,t are determined when the plant is installed and are constant over time, ${ }^{15}$ the FuelPrice ${ }_{t}$ may change every period. In the history-friendly part,

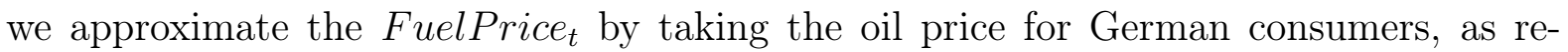
ported by the German Statistical Office (Destatis (2015)). For simplicity, we normalise the initial price value to one and adjust all other prices accordingly. From 2011 onwards we assume a random development of the fuel price:

$$
\text { FuelPrice }_{t}=\text { FuelPrice }_{t-1} \times F \text {, where } F \sim \mathcal{N}(1,0.1) \text {. }
$$

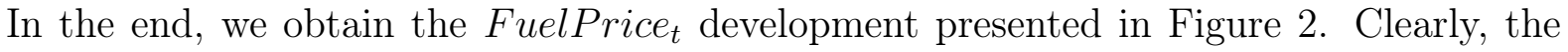
dynamics leads to changes in CostFossil $_{p, t}$ as well, but due to the fixed cost effect of CapitalCost $_{p}$ not as strong ones as the price of fossil fuels.

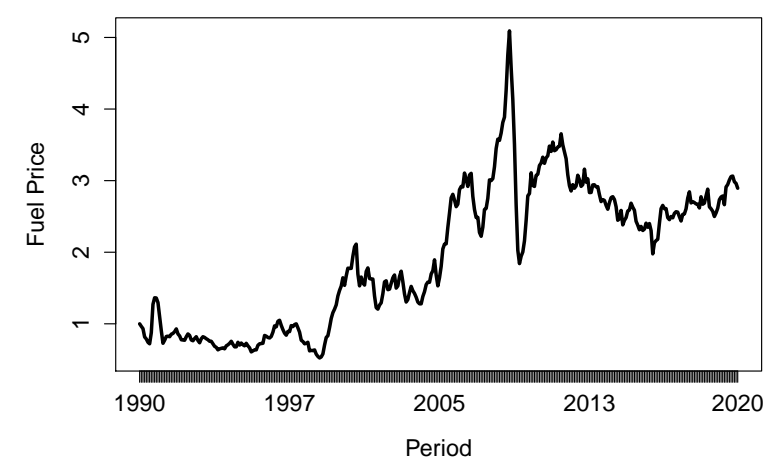

Figure 2: Development of Fuel Price over Time

\subsubsection{Equipment Manufacturers}

Manufacturers produce the equipment necessary for electricity generation and storage. There is only one manufacturer present for each technology. This is made to avoid unnecessary complexity in two aspects. On the one hand, modeling a number of manufacturers per technology would also require competitive and cooperative structures among these manufacturers. On the other hand, if manufacturers could sell more than one technology,

\footnotetext{
${ }^{14}$ The period in which the producers try to earn back the money invested is assumed to be equal to the life expectancy of the power plant, and that the costs are distributed equally among the lifetime, so that the capital costs do not change over time.

${ }^{15}$ Since the power plants are installed at different times (at the beginning of the simulation, the age of the power plants present is heterogeneous) and manufacturer of fossil plants experiences (although small) learning effects from their production (more on this in Section 2.3), there is small heterogeneity in investment costs and efficiency levels, resulting in slightly heterogeneous prices.
} 
it would be necessary to create a decision mechanism in which technology R\&D is done. ${ }^{16}$

There is little heterogeneity in the structure of the individual manufacturers. One difference comes from how much equipment a manufacturer has sold in the past (which is linked to how long she was operating in the market). The fossil producer is assumed to have been in the market for a long time by 1990, which means that it had time to improve its technology via innovation and learning (more details on this in Section 2.3). The manufacturer for REGT enters the market right at the beginning of the simulation, while the storage manufacturer only enters after storage technology becomes available.

Based on the demand in the past, each manufacturer adjusts her production capacity: increase if the demand for installation exceeds this capacity, and reduced if demand is too low for several consecutive periods. This approach is inspired by the neo-Austrian capital theory (see Faber and Proops, 1991). The number of past periods considered when deciding upon capacity change $S$ and the extent to which production capacity can be changed are parameters of the simulation. In default, it is assumed that manufacturers change their capacity according to the mean difference between demand for installations and production capacity over the last five years:

$$
\text { CapacityChange }_{m, t}=\sum_{\iota=1}^{S} \frac{\text { DemandPlant }_{m, t-\iota}-\text { Capacity }_{m, t-\iota}}{S},
$$

where DemandPlant Depit depicts the number of installations actors demand from equip-

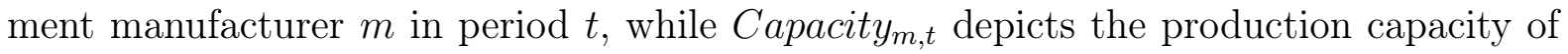
the manufacturer $m$ in period $t$. Thus, manufacturers are assumed to have adaptive expectations. The maximum increase and decrease in production capacity per period are symmetric, meaning that capacity can be at best doubled and at worst halved.

\subsection{Innovation and Learning}

Innovation and learning are an important part of the model since they can alter the competitiveness of different technologies by making them cheaper or more efficient.17 Innovative activity in this model makes the technology more efficient. The innovative step is calculated based on the amount of money invested in R\&D:

$$
\text { Efficiency }_{m, t}=\text { Efficiency }_{m, t-1}+\max \left(Z_{m, t}, 0\right),
$$

where $Z \sim \mathcal{N}\left(\frac{\log _{10}\left(\text { Invest }_{m, t}\right) \times 0.005}{\text { Efficiency }_{m, t-1}}, \frac{\log _{10}\left(\text { Invest }_{m, t}\right) \times 0.001}{\text { Efficiency }_{m, t-1}}\right)$ and Invest $_{m, t}=$ share $R D$

$\times$ SoldPeriod $_{m, t} \times$ InstallCost $_{m, t}$. The variable shareRD is a share of turnover manufacturers invest into R\&D, set to $5 \%$. The formula is chosen in a way that the higher the efficiency level prior to the innovation, the smaller the innovative step on average. This implies that it becomes increasingly difficult to improve a technology. As innovative activity cannot make technology worse (since in such a case the old technology is preferred), only $Z \geq 0$ are allowed.

Another source of (cost reducing) technology improvement are learning effects (e.g., van der Zwaan, 2003). In this model, learning effects are based on the cumulative number of installations sold. If the number of plants sold increases, the installation costs decrease.

\footnotetext{
${ }^{16}$ If the simple rule of 'R\&D expenditure equals share of turnover' would be chosen (i.e. routine-based decision), there would be no difference from assuming independent manufacturers for each technology.

${ }^{17}$ The initial value for installation costs and efficiency can be found in Table 1 in Appendix A.
} 
The effect of the number of plants sold in one period is:

$$
\text { InstallCost }_{m, t}=\text { InstallCost }_{m, t-1} \times \text { LearnRate }^{\log _{2}\left(\frac{\text { SoldPeriod }_{m, t}+\text { Stocksold }_{m, t}}{\text { StockSold }_{m, t}}\right)} .
$$

Here, the parameter LearnRate determines how fast costs decrease. For an ordinary simulation run, it is set to 0.86 , which means that every time the overall number of

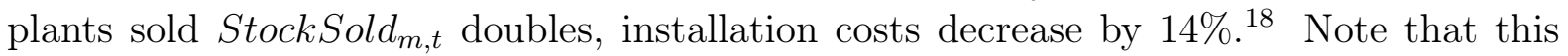
equation is the same for all manufacturers, regardless of technology. The only difference is in the number of plants assumed to be sold prior to 1990. As fossil power plants are a mature technology, a very high number of plants sold is assumed to make further learning very slow. In contrast, only few REGT installations and storage installations have been sold (a positive number necessary in equation (15)), allowing for strong learning effects. For an ordinary simulation run, it is assumed that this starting value is equal to three for both REGT and storage, while being equal to 250 for fossil plants.

\subsection{Markets}

The general structure of the markets can be observed in Figure 1. The two markets are connected, as the outcome of the market for electricity determines demand in the market for electricity generation equipment, while the installation of fossil power plants, REGT or storage technology alters the conditions in the electricity market. In the following, both markets are described in detail.

\subsubsection{Market for Electricity}

In the market for electricity two types of actors are present: fossil electricity producers and consumers. Producers generate electricity using fossil power plants and sell it to the consumers via the electricity grid. Since the ABM is modeled to represent the electricity market of an industrialised country, it is assumed that sufficient grid capacity is available.

Electricity can be generated both by fossil producers and by consumers who invested into REGT (becoming consumer-producers). Which one is demanded by the consumers depends on the prices, consumers' preferences and income. Consumers always want to purchase the subjectively cheapest form of electricity.

In order to allow consumer-producers to get their investment costs back, heterogeneous prices in the electricity market are allowed. These prices are individual for each 'consumer-producer' and are determined at the moment when the REGT is installed:19

$$
\text { ElecPriceREGT } T_{i}=\frac{\text { InstallCost }_{r, t}}{\text { Efficiency }, t_{r} \times \text { Life }_{r} \times 12} .
$$

The desired electricity price ElecPriceREGT is set in a way that the 'consumer-producer' will be able to earn her investments back, if she is able to sell all the electricity produced.

\footnotetext{
${ }^{18}$ In reality, the learning rate is different for each technology and there is a disagreement about the extent of the learning effect, as can be observed from the meta-study by Lindman and Söderholm (2012) for wind turbines. $14 \%$ is at the lower bound for wind and PV combined (for PV, see Candelisea et al. 2013). However, since we look at the complete costs of a REGT installation, we have to assume a lower learning rate, since not all cost components decrease as fast as the technology cost.

${ }^{19}$ Since installation costs are distributed equally among the lifetime of the REGT installations, the desired price stays constant over time.
} 
The value InstallCost $_{r, t} /$ Efficiency $_{r, t}$ denotes the levelised costs (technological characteristics of the plant installed). The costs are distributed over the lifetime of the plant, therefore this value is divided by Lif $e_{r} \times 12$ (in months). If a consumer-producer is not able to sell all her electricity to other consumers, she will feed-in the remaining electricity into the grid at the price which equals the cost of the cheapest fossil producer 20 This can be understood as consumers forming contracts among each other individually, allowing for different conditions compared to the general market. Using this mechanism, consumers with high preferences can pay higher electricity prices for the form of electricity they prefer. The consumers willing to purchase electricity from REGT can 'see' if there is supply available, so there is no uncertainty for them.

The market for electricity is progressed in the following order. At first, the "consumerproducers' (if present) try to sell their electricity. Other consumers buy this electricity if the following two conditions are fulfilled:

1. ElecPrice ElecPriceREGT $_{i} \times\left(1-\right.$ PrefEP$\left._{i}\right)$,

2. $\frac{\text { SIncome }_{i}}{12}>\left(\right.$ ElecPriceREGT $_{j} \times$ NetDemand $_{i}+\left(\right.$ ElecPriceREGT $_{i}+$ CostStorage $\left._{i}\right) \times$ SelfConsumption $\left._{i}\right)$.

Here ElecPrice ${ }_{t}$ is the electricity price consumers have to pay when buying electricity from the grid, ${ }^{21}$ while the cost of storage per unit of electricity is calculated from:

$$
\text { CostStorage }_{i}=\frac{\text { InstallCost }_{s, t}}{\text { Efficiency }_{s, t} \times \text { Life }_{s} \times 12},
$$

which is analogous to (16). Consumers acquiring storage plants have to add the cost of storage in (17) to the price of REGT electricity in (16).

In sum, consumers buying (potentially more expansive) REGT electricity do not spend more than threshold $\phi$ of their income on electricity (including the electricity they produce and consume themselves) ${ }^{22}$ Otherwise, they have to switch from REGT to the fossil electricity. The 'general' market price for electricity ElecPriceMarket ${ }_{t}$ is determined by a merit-order (e.g., Sensfußet al., 2008). This means that the electricity producers feed-in their electricity according to their cost in ascending order. ElecPriceMarket $t_{t}$ is equal to the CostFossil Cof $_{\text {of }}$ of the producers with the highest price who can feed-in electricity. Power plants with costs below the electricity price run the entire time, resulting in an uptime value equal one for this period. The power plants that produce at costs equal to the electricity price (the power plants which feed-in last), might not face sufficient demand to run the entire time. Therefore, their up-time is determined by how much residual electricity demand they face compared to the maximum amount they could generate.

On ElecPrice Market t $_{t}$ markup is added if there are policy instruments in place, as described in Section 2.5:

$$
\text { ElecPrice }_{t}=\text { ElecPriceMarket }_{t}+\text { MarkupPolicy }_{t}
$$

Here, MarkupPolicyt denotes the cost of all policy instruments applied, calculated on a monthly basis and divided by the NetDemand $i$ in the electricity grid. With this notation, the price of each unit of electricity bought from the grid is increased by the

\footnotetext{
${ }^{20}$ This assumption is made to ensure that the consumer-producers can feed-in all their electricity instead of loosing it and making (even larger) losses.

${ }^{21}$ Note that ElecPriceREGT can be different for each 'consumer-producer', so that it is possible that some can sell their electricity at their desired price level while some cannot.

${ }^{22}$ The cost of storage is included as no household can self-consume without installing storage capacity.
} 
same markup. Electricity generated from 'consumer-producers', which is directly sold to other consumers on a bilateral basis, is not increased by MarkupPolicy, as the policy maker does not aim to increase the cost disadvantage of electricity from REGT further. Consumers, who do not buy electricity directly from 'consumer-producers' or are not able to satisfy their demand by self-production, have to pay ElecPrice ${ }_{t}$ for the electricity they consume, even if the total expenses result in a higher share than $\phi$ of their income. ${ }^{23}$

\subsubsection{Market for Electricity Generation Equipment}

In this market, all actor types are present. The manufacturers sell their individual equipment to fossil producers and those consumers investing into REGT or storage technology.

The decision of consumers to invest into REGT and storage technology is based on a number of factors. For REGT, consumers will only invest if they would buy electricity generated from REGT based on the current technology. Therefore, the precondition to invest is the same as the decision rule to consume electricity generated from other 'consumer-producers' in Section 2.4.1. However, there are three additional restrictions. First, a consumer will not invest if all of her electricity demand is satisfied by electricity generated from REGT from other 'consumer-producers', so NetDemand D $_{i}>0$ must $^{-}$ hold. ${ }^{24}$ Second, the consumer must have sufficient funds to purchase at least one REGT installation, preventing poor consumers from investing into REGT (we assume that only consumers with income equal to the price of a REGT plant Income $_{i}>$ InstallCost $_{r, t}$ can invest into REGT). Third, the consumer should have sufficient space available.

For storage technology, the decision process is similar. The consumers will invest if the following three conditions are fulfilled:

1. ElecPrice $_{\text { }}>$ ElecPriceREGT $_{i} \times\left(1-\right.$ PrefEP $\left._{i}\right)+$ CostStorage $_{i} \times\left(1-\right.$ PrefAutarky $\left._{i}\right)$,

2. $\frac{\text { Income }_{i}}{12}>\left(\right.$ ElecPriceREGT $_{i} \times$ NetDemand $_{i}+\left(\right.$ ElecPriceREGT $_{i}+$ CostStorage $\left._{i}\right) \times$ SelfConsumption $\left._{i}\right)$,

3. NumberOf StoragePlantsInstalled ${ }_{i} \times$ Efficiency $_{s, i}<$ NumberOfREGTPlantsInstalled ${ }_{i} \times$ Efficiency $_{r, i}$.

The rules stated ensure that i) the household finds the cost of self-produced and stored electricity subjectively cheaper than the one from the grid; ii) she can finance the additional consumption of the self-produced electricity not surpassing her threshold of income; iii) the number and efficiency of storage plants already installed does not yet cover the amount of electricity (maximally) produced by REGT plants installed.

Manufacturers always sell up-to-date equipment at current prices, so there is no stock. All equipment produced in a specific period is also sold. Since manufacturers only start producing after they face demand, there is no risk of unsold products.

\subsection{Policy Intervention}

Policy intervention plays a central role in this model. Historically, policy intervention was needed (Jacobsson and Lauber, 2006) to initiate and foster the transition towards the usage of electricity generated from REGT. Even though there is a number of 'ecowarriors' present in the model, their influence is not sufficient to induce innovation and

\footnotetext{
${ }^{23}$ Thus, the threshold $\phi$ is effective only when consumers choose between the two alternatives and tend to select a more expansive one. If, however, these consumers lack funds to pay even for objectively cheapest electricity, then they spend more than this threshold (their number is reported in Figure 5).

${ }^{24}$ Otherwise she assumes a sufficient amount of renewable electricity is present and does not act.
} 
learning to an extent that would make a general transition possible. Therefore, at some point the policy maker may decide to intervene and support the diffusion of REGT.

We assume that the policy maker aims to foster the transition towards electricity from REGT, in particular, to reach the $26 \%$ share of electricity from REGT of all consumed electricity by 2020. This aim is fixed, so that there are no changes due to political elections or other changes in government. Apart from this, policy maker aims to preserve the stability of the electricity grid. In the model, stability is measured as the share of unstable electricity supply inside the electricity grid. The policy maker is willing to keep the stability of electricity supply high, which conflicts with the goal of increasing the share of electricity from REGT ${ }^{25}$ Also, the transition should be as steady as possible.

To limit the choice options, the policy maker can only apply a pre-specified collection of policy instruments (either separately or as a mix). A mix of different instruments is sometimes considered to be more efficient than single instruments with the same commitment level (Rogge and Reichardt, 2015). The costs of these instruments are laid as a surcharge upon the electricity price for electricity distributed via the grid, i.e. among the consumers who buy electricity from the grid (equation (18)).

Most of the policy instruments can be applied to all technologies present in the ABM. However, since the fossil technology is already mature and supplies the whole market by 1990, there is no policy support for it ${ }^{26}$

\section{Public R\&D}

The most basic form of policy intervention is research performed by public actors. This research can be either basic or applied. Basic research has the sole purpose of making the storage technology available. Without basic research, there is no chance storage will be discovered (see Section 2.1). Applied public R\&D works in the same way as private R\&D (described in Section 2.3) but is conducted separately. The policy maker can choose in every period $t$ the budget invested in technology $m{ }^{27}$ Results of public R\&D in terms of technology advances in efficiency are transferred to technology producers at no cost.

\section{R\&D Subsidies}

Instead of performing $R \& D$ in the public sector, another policy option is financing private R\&D. This instrument simply adds funds for research to the respective share of turnover which the manufacturer invests. The sum available for innovative activities changes to:

$$
\text { Invest Sub }_{m, t}=\text { Invest }_{m, t}+\text { StateFunds } s_{m, t},
$$

where StateFunds $s_{m, t}$ is the R\&D subsidy for a specific technology.

\section{REGT Installation Subsidies}

There are several diffusion-oriented policy instruments possible. The most straightforward is to subsidise the installation cost of REGT or storage technology, which increases

\footnotetext{
${ }^{25}$ The only exception is when the REGT electricity is sufficiently supported by the storage capacities of consumers. In that case, REGT becomes automatically stable.

${ }^{26}$ Of course, in reality there is a lot of institutional support and subsidies for fossil power plants. However, to simplify the search for an optimal policy mix, currently all the policy instruments are aimed at improving REGT and storage technology.

${ }^{27}$ Public R\&D on storage technology can be applied only after the technology is introduced.
} 
the incentive for consumers to install them. In the model, this policy instrument is modeled to decrease the price a consumer has to pay by a certain percentage. Note that the revenues of the manufacturer do not change:

$$
\text { PInstall }_{m, t}=\text { InstallCost }_{m, t} \times\left(1-\text { SubInstall }_{m, t}\right) .
$$

Here PInstall P $_{m, t}$ is the price for a consumer, while InstallCost In,t $_{\text {is }}$ ise price at which the manufacturer is selling. The variable $S_{u b \text { Install }_{m, t}}$ determines the percentage of the installation cost financed by the state and is dependent on the levelised cost of technology $m$ at time $t$ observed by the government. The actual value is computed from:

$$
\operatorname{SubInstall}_{m, t}=\min \left(S_{m, t}, 0.9\right),
$$

where $S_{m, t} \sim \mathcal{N}\left(\frac{\text { InstallCost }_{m, t}}{\text { Efficiency }_{m, t}} \times \frac{1}{\text { InstallCost }_{m, 0}}, \frac{\text { InstallCost }_{m, t}}{\text { Efficiency }_{m, t}} \times \frac{1}{\text { InstallCost }_{m, 0}} / 10\right)$. The government here tries to keep to subsidy level stable in relation to the decreasing prices, since it has to offer less subsidies if the technology becomes cheaper and more efficient.

\section{Feed-in Tariff}

For Germany, the most important policy instrument was and remains a feed-in tariff (FIT) (see Jacobsson and Lauber, 2006). FIT guarantees the feed-in of electricity generated from REGT at a fixed price. This removes the uncertainty related to the investment into REGT, namely if there are consumers willing to purchase electricity from REGT at a sufficiently high price. The decision to invest into REGT becomes a simple decision based on net-present value, as both cost of installation and expected income from the installation become known ${ }^{28}$ Since the installation costs are covered by FIT, the 'consumer-producers' do not need a positive electricity price anymore and feed-in electricity into the market at zero marginal costs, crowding out electricity from fossil power plants. Another side consequence of FIT is that it reduces the incentive to self-consume REGT electricity, if FIT granted is higher than the electricity price consumers have to pay. The height of FIT is calculated in the following way:

$$
F I T=\frac{\text { InstallCost }_{r, t}}{\text { Efficiency }_{r, t} \times \text { Life }_{r} \times 12 \times \text { mean }(\text { Irradiation })} .
$$

Here, FIT denotes the amount of money consumer-producers get per unit of electricity fed-in. FIT is dependent on the levelised cost of the installation $\left(\frac{\text { InstallCost }_{r, t}}{\text { Efficiencyr,t }_{r, t}}\right)$. Also, FIT is granted over the entire lifetime of the REGT installation and paid on a monthly basis ( Life $e_{r} \times 12$ ). To avoid all consumers accepting the FIT, it is divided by the mean irradiation of consumers, which means that only people living in locations suitable for REGT will be able to benefit from the FIT. Since the extent of the FIT is calculated from the mean irradiation, consumers enjoying irradiation above average can benefit from it.

Although further policy instruments could be implemented (such as a carbon tax), their calibration becomes increasingly complex while justification of their relevance in the past is rather questionable. Therefore, we leave their analysis for further research.

\footnotetext{
${ }^{28}$ Note that this policy instrument greatly reduces the importance of preferences for environmental protection, since now even people with low preferences might have an incentive to invest into REGT.
} 


\subsection{Ordering of the Simulation Steps}

In the $\mathrm{ABM}$, the following sequence of simulation steps is adopted:

1. Set all exogenous parameters; allocate to actors their characteristics.

2. Each month sell electricity to consumers.

3. At the end of each year do the following:

- Electricity producers and consumers buy new plants if necessary.

- Equipment manufacturers invest in R\&D.

- Policy maker updates her policy intervention.

4. After a pre-specified number of periods $T$ stop the ABM and report results on:

- the diffusion of REGT and the stability of electricity production,

- income/losses generated by consumers from investing into REGT technologies,

- electricity prices.

\section{Robustness Analysis and Empirical Verification}

In this section, tests with alternative parameter settings are performed to calibrate the model as not all parameters can be constructed from historical data. While there is information about, e.g., income structure or the speed of learning, other parameter values are unknown, as for example, the distribution of preferences, where some assumptions have to be made ( discussed in Section 2.2.1). In those cases we follow Malerba et al. (2008) and other history-friendly models in not attempting detailed calibration of all parameters: 'Because most parameters fall into groups within a particular mechanism in the model, common-sense guidance is available for choosing plausible orders of magnitude'.

The model has been calibrated with the parameter settings presented in Table 1 in Appendix A. The parameters were chosen to represent the conditions of Germany in the 1990s. The parameters for fossil producers are set that every consumer can afford to satisfy her electricity demand at the beginning of the simulation without spending more than $\phi \%$ of her income on electricity. This is partly due to the high efficiency of fossil plants, but also due to the low initial price for fossil fuels. The initial values for price and efficiency of REGT, as well as the preferences of consumers, are chosen in a way to allow consumers with high preferences to install REGT, but make it unattractive for others. ${ }^{29}$ The technological characteristics, however, can be improved substantially making REGT electricity more attractive and replicating the progress of the technology in the last two decades. Due to the parameters chosen for innovation and learning, it is very unlikely that REGT overcome their cost-disadvantage without governmental support. The figures on space available (for consumers) and its irradiation are calibrated to make possible all demand for electricity to be satisfied from REGT sources, if there are substantial improvements in the efficiency of REGT 30

\footnotetext{
${ }^{29}$ This reflects the lack of cost competitiveness of REGT compared to fossil fuels, especially at the beginning of 1990s.

${ }^{30}$ The REGT technology has to be improved by about $80 \%$ (in terms of efficiency) so that the complete demand can be satisfied from REGT-installations.
} 
With the set of parameters chosen, there is no meaningful diffusion of REGT without public support (Figure 14 in Appendix B). The only investment into REGT-installations (bottom right chart) is from the 'eco-warriors', but their number is not sufficient to induce adequate learning effects or innovation to improve REGT to a level where it can compete with fossil power plants, even though there are some improvements in efficiency of REGT plants and a significant drop in prices, caused by early learning effects ${ }^{31}$ Therefore, the share of electricity generated from REGT stagnates below 1\% (top left chart).

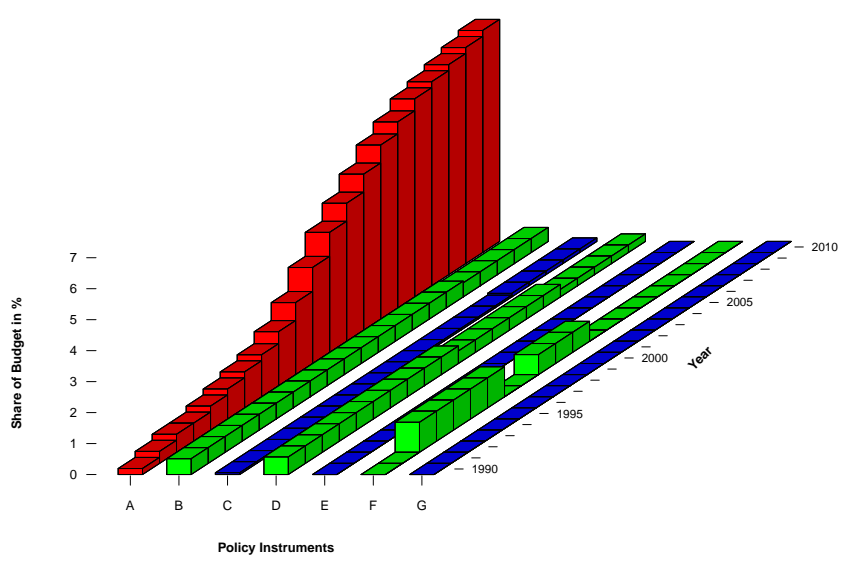

$$
\begin{aligned}
& \text { A }=\text { FIT for electricity from REGT } \\
& B=\text { Public R\&D (REGT) } \\
& \text { C }=\text { Public R\&D (Storage) } \\
& \text { D }=\text { R\&D Subsidy (REGT) } \\
& \text { E }=\text { R\&D Subsidy (Storage) } \\
& \text { F }=\text { Installation Subsidy (REGT) } \\
& \text { G }=\text { Installation Subsidy (Storage) }
\end{aligned}
$$

Figure 3: Policy Mix for History-Friendly Runs

To generate a history-friendly simulation run, which can serve as a basis for our optimal policy mix identification, we run the first 20 years of our simulation with a predefined set of policy interventions and the values presented in Table 1 in Appendix A. For the policy interventions, we try to mimic the order in which different policy instruments were applied (see, e.g. Cantner et al., ming) : public R\&D and R\&D subsidies are present over the whole period, with increasing amount of money invested over time. Installation subsidies are introduced periodically (since they were usually subsidy programs with a finite time frame) with varying amount of money invested. The subsidy per REGT installation decreases over time, as the decreasing cost and increasing efficiency of the plants lower the subsidy necessary to induce consumers to invest (this consequently leads to more installations supported with the same governmental investment). Since the first German FIT (Electricity Feed-in Law - 'Stromeinspeisegesetz') was introduced already in 1991 (see, e.g., Jacobsson and Lauber, 2006 and Cantner et al., ming), FIT is active all the time in our model. However, the first FIT provided sufficient incentives only for some technologies. More effective FIT was introduced in 2000, the Renewable Energy Sources Act ('Erneuerbare Energien Gesetz', EEG), which provided sufficient incentives for most REGT. We replicate this by choosing small sums spent on FIT in the first years, but then strongly increasing them so that more consumers can apply for FIT over time. ${ }^{32}$ To summarize, the amount of funds invested to support REGT technologies increase over time, particularly after an effective FIT is introduced in 2000 (Figure 3).

\footnotetext{
${ }^{31}$ Due to the small initial number of installed plants chosen, even low production numbers allow manufacturers to achieve strong learning effects.

${ }^{32}$ Note that the money which can be spent on policy intervention is pre-specified for each period. By changing these values, the focus of the policy mix can be shifted between different instruments.
} 
We take as a basis the simulation run producing the median share of renewable electricity in the electricity market over 101 replications ${ }^{33}$ This share is $8.3 \%$, which is nearly identical to the actual value for Germany in 2010 (according to the German Federal Minstry for the Environment and Nuclear Safety (2012)). The development over time is very similar, as can be observed from the top left plot in Figure $44^{34}$
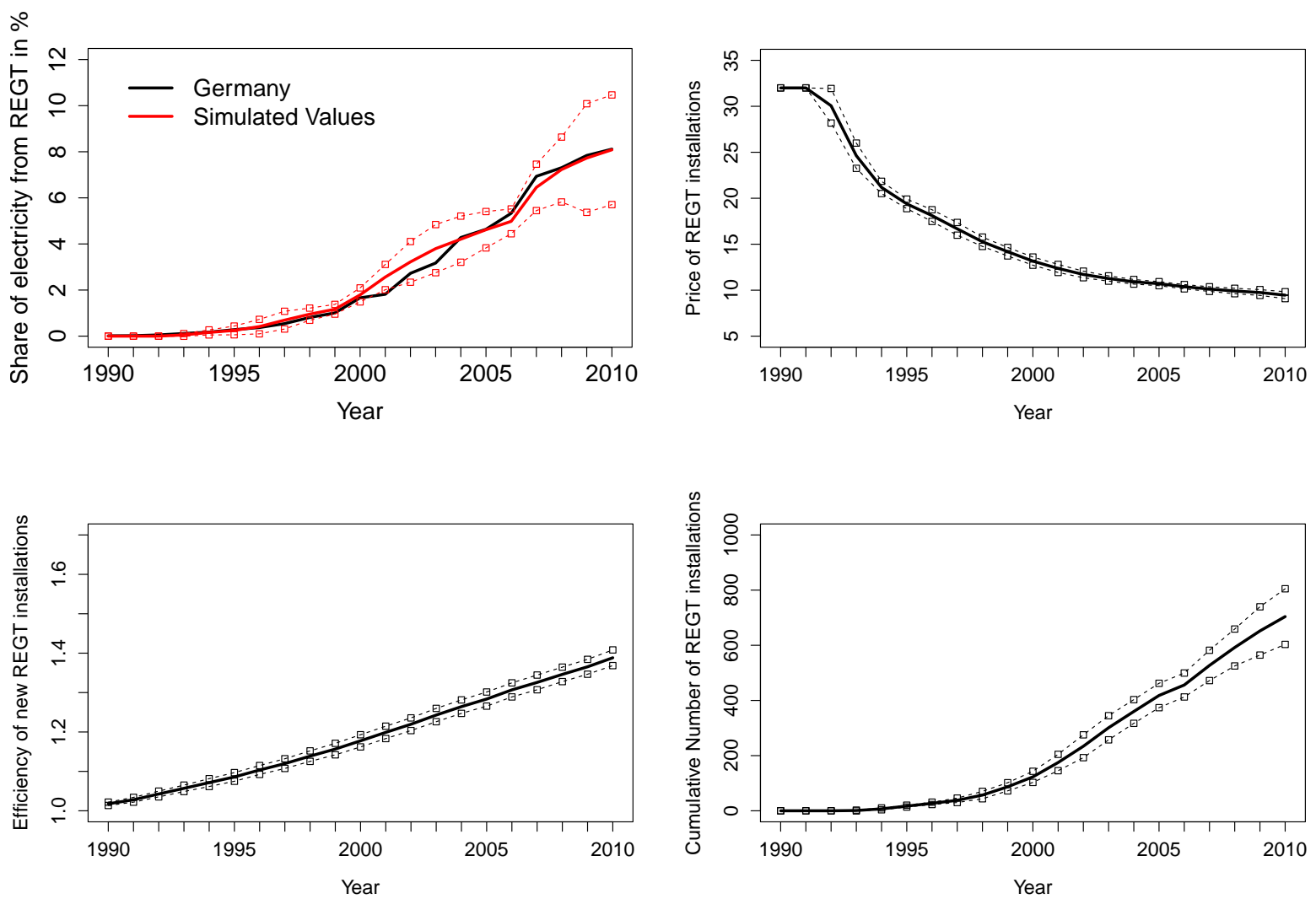

Figure 4: Characteristics of REGT evolution with HF policy support

Note: In all charts the median run $+/$ - two standard deviations are presented.

Since this 'history-friendly' simulation run serves as a basis for optimal policy mix identification by DE, it is useful to show some developments and final values at $t=240$ (at the end of 20 years period, $T_{1}$ ). As can be observed from the bottom right chart in Figure 4, the number of REGT installations increases steadily, closely correlated with the share of electricity generated from REGT. This fact is hardly surprising, since the electricity must be generated from the installations. From the bottom left chart in Figure 4 we see that the efficiency (electricity generated per REGT installation) increases over time, by about $40 \%$ in 20 years. The variance between single runs in the top charts of Figure 4 spurs mainly from the stochastic nature of efficiency improvements. More improvements imply less REGT plants have to be installed to generate a certain amount of electricity, which influences the profitability of single plants and therefore the costcompetitiveness of REGT in comparison to fossil fuels. The price of REGT installation

\footnotetext{
${ }^{33}$ It is not possible to take mean results of all 101 runs since we need an individual simulation result as input into the differential evolution and not averaged values. Another advantage of the median is its robustness to outliers, which is also an asset for our modeling exercise.

${ }^{34}$ The correlation between our simulation results and the German time-line is 0.98529 .
} 
decreases over time by nearly $65 \%$, so that the cost per unit of electricity generated is reduced by nearly $80 \%$ (i.e. combined effect from efficiency and cost improvement), which is more than the historical decrease of the levelised cost of wind electricity (about $60 \%$, Lantz et al., 2012), but a bit below the development for photovoltaics (above $80 \%$, calculated from Stubenrauch, 2003, Wissing, 2013).

Storage technology was introduced in the simulation by public R\&D in 2003. However, due to still high costs, only 4 consumers installed a storage facility. Nearly all improvement to the technology is from public R\&D, which increased efficiency by about $6 \%$. The cost of storage technology decreased by about $20 \%$, due to the very strong initial learning effects. However, since there is large room for further improvement, storage can become important in the near future (in the period 2011-2020, where we attempt to identify an optimal policy mix).

Out of 1000 consumers, 148 did invest into REGT, but 91 of these consumers did not use all their space available due to the income constraint. If they have to replace their installations after 20 years, they will likely use more space due to the reduced price of REGT. Out of the 148 consumers who have already installed REGT, 115 were granted FIT, which means that only 33 consumers did invest without the incentive. However, some of them could have invested due to an investment subsidy that reduced prices. While most 'eco-warriors' invested (47 out of 50) in REGT, 26 of them accepted FIT. In addition, 7 'eco-warriors' also used a subsidy to install REGT. Since at least some 'eco-warriors' would also have invested without FIT, the existence of FIT is crowding-out voluntary investment. In particular, as can be observed from the left chart of Figure 13 in Appendix B, the oldest installations were accepting FIT. Only after some time consumers (including 'eco-warriors') started also investing on their own (next to accepting FIT but not rejecting it when available), as the technology improvements allowed more consumers (than the amount of FIT support available) to invest. This indicates that the existence of high FIT may be initially beneficial (to help the REGT technology to improve), but is crowding out other incentives to invest later on, since even consumers who would invest on their own are better off if they accept FIT.

The electricity price from the grid increases over time, as can be observed from the right chart of Figure 13. However, the reason for this increase is mainly caused by the increase in prices for fossil fuels, which show an increase up to factor five throughout the simulation. The price effect of public action is low in the first half of the simulation (with the exception of a very strong subsidy program at the beginning), but increases steadily in the second half. At the end, it accounts for about one-fifth of the electricity price and is expected to remain high due to the long term character of FIT subsidy (granted over the entire lifetime of REGT installations, Section 2.5). As a consequence, the policy instruments already being applied will affect the REGT diffusion in the near future (2011-2020) making installations of renewable technologies even more attractive.

Figure 5 demonstrates that, averaged over the whole history-friendly period, only poor consumers with relatively high electricity demand become 'energy poor' (left chart). Together with the right chart illustrating the cost of policy intervention compared to income, it becomes clear that poorest households have to pay disproportionally more for the public support of REGT. There are several reasons for this finding. First, since electricity demand is only weakly correlated with income, the effect of rising electricity price due to policy instruments is largest for poor consumers. This regressive effect, especially of FIT, has also been shown for the German case (e.g., Lehr and Drosdowski, 2013). Second, consumers with less income have fewer opportunities to invest into REGT 
and Storage (mainly due to income and space restrictions) and, therefore, are less likely to receive public support. As a consequence, poor consumers are most vulnerable to the electricity price dynamics observed.
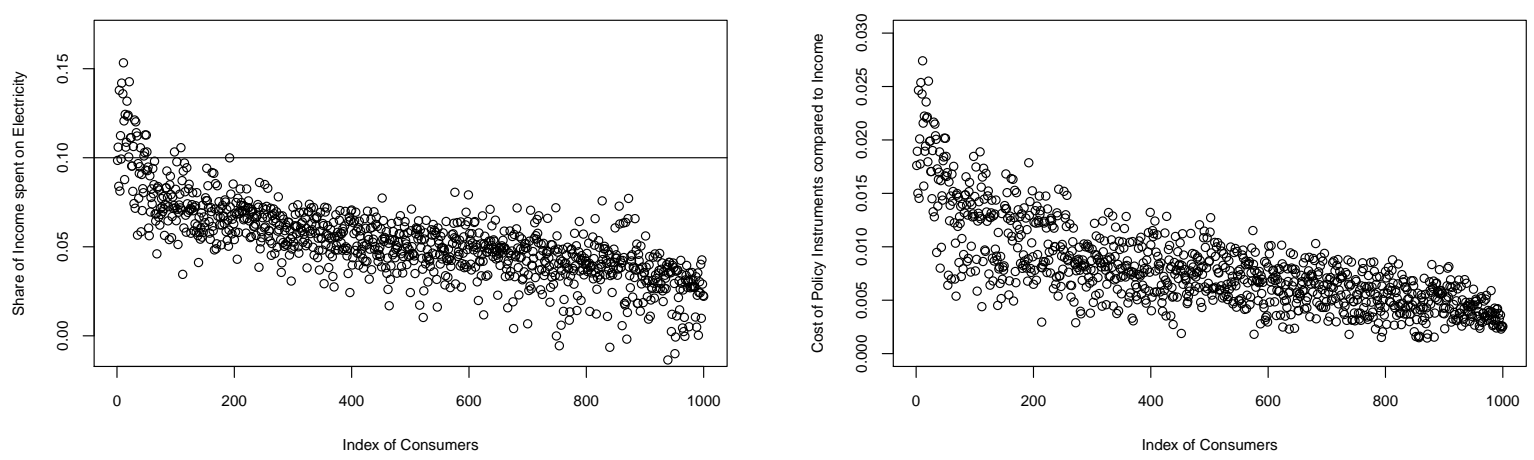

Figure 5: Income Spent on electricity

Note: Consumers in this figure are ordered in ascending order by their income.

Another purpose of numerical experiments is sensitivity analysis. Here, we aim to find out how robust the simulation results are to changes in parameters. Although it is impossible to discuss each parameter in detail, we would like to stress only the most important ones. First, naturally our results are sensitive towards changes in the initial values concerning costs and efficiency. Also, the extent to which innovation and learning can reduce those characteristics over time have a strong impact on the results (which is not surprising given the decisions of consumers are based on the comparison of the two technologies). One more important parameter worth mentioning is the distribution of environmental preferences, because the model results may be driven by the exact distribution of those preferences among consumers. In Figure 15 in Appendix C, the effect of reassigning those preferences prior to each simulation run is demonstrated. The black lines show the results for the standard parameter distribution used in nearly all runs presented in the present study, while the red lines illustrate the results from the same parameters except that income and REGT preferences are newly re-distributed before each simulation restart (just ensuring that the two are weakly correlated). Both diffusion patterns look very similar illustrating that our model results are robust for different combination of income and environmental preferences among individual consumers. Thus, we conclude that the choice of the parameters is accurate for the purpose of our study since i) many of them we tune based on empirical estimates; ii) we can replicate some of the key empirical figures (diffusion of REGT, improvement in REGT levelised cost) and stylised facts (e.g., asymmetric distribution of policy costs among electricity consumers) in the history-friendly exercise; iii) we demonstrate that the results are sufficiently stable to changes in consumer individual characteristics.

\section{Counterfactual Analysis by Differential Evolution}

In this section we take a challenge in 'looking further ahead' instead of only in the 'rearview mirror' as has been put by Garavaglia (2010). A necessary limitation of the counterfactual (i.e. 'what if' ) analysis provided below is that it provides sufficient (in 
the structure of the present study) but not necessary condition for a certain outcome. Therefore, results shall be considered with caution. Nevertheless, we believe that this is a very promising direction of research, particularly in the line of history-friendly modeling literature, fostering the discussion on the normative role of modeling in economics.

To identify an optimal policy mix we apply an exercise from the optimal control literature (see, e.g., Blueschke-Nikolaeva et al., 2012), where a set of controls is optimised to achieve the states as close as possible to policy targets. An important difference is that since we fix the overall budget of policy interventions ${ }^{35}$ Therefore, the controls themselves do not contribute to an objective function value, but only the corresponding states achieved. The states in our study are of two types only: the difference between the targeted and reached level of REGT on the market and a penalty added in case the energy grid's stability becomes vulnerable.

Another difference to optimal control literature consists in taking only the final year of simulation into account in evaluating the objective function. Thus, e.g. diffusion may be slow or fast, but the policy maker is solely interested in the final outcome.

$$
\min (J)=\left(\text { Diffusion }^{\text {Target }}-\text { Diffusion }^{\text {Actual }}\right)-\log (\text { Stability })
$$

where Diffusion ${ }^{\text {Target }}$ is the target set by policy maker for the system at the final period $T_{2}$ (i.e. $26 \%$ diffusion of the REGT technology), while Diffusion ${ }^{\text {Actual }}$ is the level of the REGT diffusion achieved, respectively. Thus, in our case a positive deviation from the target value is penalised, while a negative deviation (i.e. an 'over-achievement') reduces the value of the objective function, as the policy makers are even more successful with their policy intervention then expected. $\log$ (Stability) represents the penalty on grid instability, which is measured as a logarithm of the percentage of electricity produced either out of fossil sources or supported by sufficient storage capacity ${ }^{36}$

\subsection{Differential Evolution}

To optimise the function, a Differential Evolution (DE) algorithm proposed by Storn and Price (1997) is used. The choice in favor of a so-called heuristic optimisation method is due to i) large flexibility in terms of formulating our ABM and its main objective function with no essential assumptions about the optimisation model (for more details read Gilli and Schumann (2014)) and ii) not necessarily 'well-behaved' search space of our problem (with non-linearities and multiple local optima), where classical methods are inappropriate. Since computing power has increased dramatically over the last decades, it is also less a problem of time to optimise our ABM by DE 37

\footnotetext{
${ }^{35}$ In particular, the yearly budget for the last ten years is taken close to the value observed in the last year of the history-friendly part (i.e. 2010) (thus, we assume that in the future the yearly sum of support should not increase further). For the period of 30 years we consider the sum of the history-friendly budget and the one we fix for the last ten years, thus ensuring comparability between the exercises in terms of the total budget spent on REGT support. The overall extent of public support for the history-friendly run and the DE is shown in Table 1 in Appendix A.

${ }^{36} \mathrm{It}$ is easy to see that objective function is falling in Diffusion ${ }^{\text {Actual }}$ with constant marginal return for each additional percent of electricity produced by means of REGT, while $J$ is also falling in Stability with the difference that of diminishing marginal returns, i.e the more stable situation we have, the less every additional percent of unstable electricity supply is penalized. Note that the form of the objective function has been selected to be simple. It can be easily substituted if necessary. However, in the following we illustrate that it well balances the diffusion and stability in a 30-year experiment.

${ }^{37}$ Our ABM is written in $\mathrm{R}$. A single restart of the ABM for the parameter setting stated requires from 6 to 30 seconds using R 3.1.1 and Pentium IV $3.3 \mathrm{GHz}$ (depending on the policy mix and planning
} 
DE is a population-based optimisation technique for continuous objective functions and only few tuning parameters to initialise (Blueschke et al. 2013$)$. In short, starting with an initial population of random solutions (line 2 in Algorithm 1), DE updates this population by linear combination (line 7) and crossover (line 9) of four different solution vectors into one, and selects the fittest solutions among the original and the updated population. This continues until some stopping criterion is met. More specifically, DE starts with a randomly initialised set of candidate solutions $P_{j, t, i}^{(1)}(j=1, \ldots, K ; t=$ $\left.1, \ldots, T^{D E}, i=1, \ldots, p\right)$ of the $K \times T^{D E} \times p$ size, where $K \times T^{D E}$ is the dimension of a single candidate solution, with $K=7$ being the number of control variables (policy intervention options in our case) and $T^{D E}$ - the size of the planning horizon (120 or 360 months), and $p$ is the population size. Based on the tuning exercise described in (Blueschke et al. 2013, p. 825-826), $p=10 \times K$, the shrinkage parameter $F$ is set to 0.8 , while the crossover rate $C R=0.3$. A detailed discussion on how DE can be applied and tuned for optimal control problems is provided in Blueschke et al. (2013).

As for the DE stopping criterion, this has to: i) ensure that DE population of solutions converges to an optimum (local or global); ii) signal DE to stop once the convergence is observed. Again, in line with Blueschke et al. (2013), we set an upper limit on the number of DE generations to be performed within one restart ( $G^{\max }$ equal to 500 ), but at the same time control for convergence within the population by looking on the candidates' objective values. In particular, DE algorithm stops if $50 \%$ of solutions in the population reach a deviation less then $10^{-9}$ from the best solution available. In addition, if for 100 periods more than $50 \%$ of solutions in the population do not improve, the algorithm also stops. Since our model contains stochastic components, one must repeat the model evaluation for each candidate solution certain number of times (3 in our case) and use their median value (more on advantages of using the least median objective value is written in Savin and Blueschke (2015)).

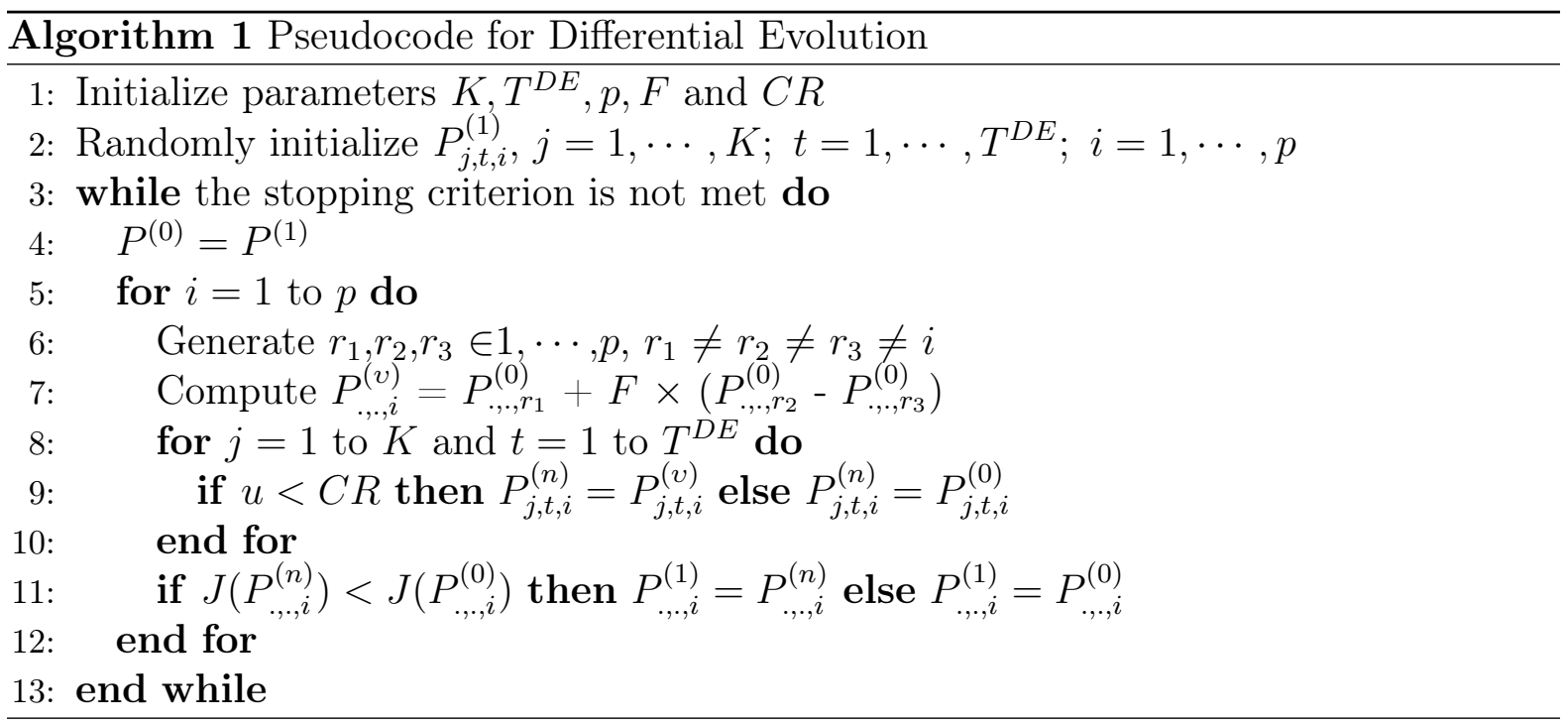

To illustrate the convergence of the DE algorithm we run a small-scale experiment with the same targets but the planning horizon of three years only (2011-2013, i.e. if the goals would have been set for 2013) also reducing the size of the DE population to $p=3 \times K$ but for 100 independent DE restarts ${ }^{38}$ Results of the experiment are

horizon considered).

${ }^{38}$ Note that although a single evaluation of the ABM takes merely seconds, a single DE run with 500 
illustrated in Figure 16 in Appendix C. In the upper left plot of the figure the cumulative distribution function for different $g$ is given, whereas the other plots are kernel density plots of objective function values identified. Increasing the number of generation the distribution shifts left and becomes less dispersed around the potential global optimum solution ${ }^{39}$ Since DE is a stochastic optimization algorithm, later on we always restart it five times and report the best solution selected.

\subsection{Outlook for 2011-2020}

We run the DE algorithm taking the history-friendly run presented in Section 3 as a basis. Here, of special importance is the policy mix applied. Assuming that the government keeps its promises, FIT introduced in former periods limits the autonomy of decision in later periods. For the policy mix candidate solutions used in our DE algorithm, we have to make sure that sufficient money is allocated on paying for the 'old' installations that were installed with FIT. This reduces the funds to be allocated for other policy instruments (or used for new installations with FIT).

As can be observed from Figure 6, the policy mix found by DE is dominated by FIT. However, this high level of FIT was predetermined by the 'history-friendly' part of the simulation and is decreasing as fast as the promise of paying FIT over a period of 20 years allows. No new FIT is granted, strongly indicating in the direction of FIT being too high before, so the money could have been spent more efficiently on other instruments.

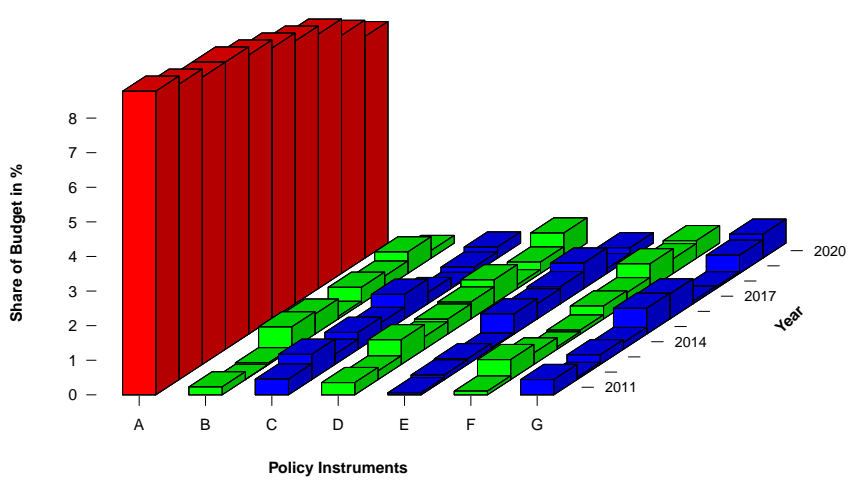

$$
\begin{aligned}
& \mathrm{A}=\text { FIT for electricity from REGT } \\
& \mathrm{B}=\text { Public R\&D (REGT) } \\
& \mathrm{C}=\text { Public R\&D (Storage) } \\
& \mathrm{D}=\text { R\&D Subsidy (REGT) } \\
& \mathrm{E}=\text { R\&D Subsidy (Storage) } \\
& \mathrm{F}=\text { Installation Subsidy (REGT) } \\
& \mathrm{G}=\text { Installation Subsidy (Storage) }
\end{aligned}
$$

Figure 6: Policy Mix derived from 10 years DE runs

Over the course of ten years, budget is spent rather evenly among the different policy instruments (with the obvious exception of FIT). There is, however, a slight advantage for storage technology, which is interesting since it shows a switch in priority of the policy maker in the model (in the 'history-friendly' part, there was very little spent on storage). The temporal distribution of the non-FIT instruments shows a slight bias towards the

generations would require $10 \times 7 \times 3 \times 500=105^{\prime} 000$ model evaluations, which makes the computation of 100 such restarts with standard office computers very expansive (several months time).

${ }^{39}$ Note that similar results in terms of the objective function are obtained by very similar solutions in terms of policy budget allocation. Thus, although one cannot guarantee that the same objective value cannot be obtained by two (very) different solutions, we compare the standard deviation of the 100 best identified $J$ values with the standard deviation among the corresponding $P_{., ., i}$ solutions, and both are of the order $10^{-5}$. 
beginning, which means that it seems optimal to spend the budget early on, given that technology costs have already decreased substantially in the 'history-friendly' period.

The diffusion of REGT continuous in a nearly linear manner and reaches about $19 \%$ in the last year, meaning that the government is not able to reach its diffusion goal of $26 \%$ diffusion with the budget limitation and policy mix combination. ${ }^{40}$ The price of REGT decreases by $20 \%$ over the course of ten year (compared to the value at the end of the history-friendly run), while efficiency increases by 20 percentage points and is now $60 \%$ higher than at the beginning of the history-friendly runs. All in all, 234 consumers installed REGT installation, which is very close to $25 \%$ of the population and an increase by $58 \%$ compared to the end of the 'history-friendly' run.

$85.5 \%$ of all electricity produced is considered stable. Here, most of the stable electricity still comes from the fossil plants. However, the number of consumers who have installed a storage facility (131) is quite high. This means that more than half of all consumers who invested into REGT also have installed a storage solution. However, only 8 consumers did install a sufficient amount of REGT installations and storage facilities to completely cover their demand (allowing them to become autarkic from the grid). All in all, only about one fourth of all electricity generated from REGT can be stabilised with the installed storage. The cost of the storage technology decreased by $\approx 50 \%$ compared to the end of the 'history-friendly' runs, while the efficiency increased by about $20 \%$.

\section{Scenario with increased budget}

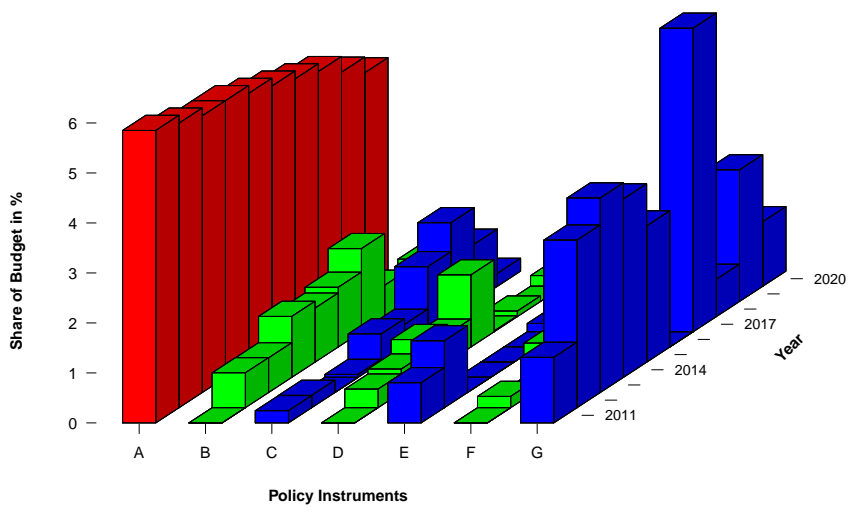

$$
\begin{aligned}
& \mathrm{A}=\text { FIT for electricity from REGT } \\
& \mathrm{B}=\text { Public R\&D (REGT) } \\
& \mathrm{C}=\text { Public R\&D (Storage) } \\
& \mathrm{D}=\text { R\&D Subsidy (REGT) } \\
& \mathrm{E}=\text { R\&D Subsidy (Storage) } \\
& \mathrm{F}=\text { Installation Subsidy (REGT) } \\
& \mathrm{G}=\text { Installation Subsidy (Storage) }
\end{aligned}
$$

Figure 7: Policy Mix derived from 10 years DE runs (increased budget)

The extraordinary high share of spending for FIT raises the question whether the budget restriction is too strict. Therefore, we repeat the experiment with a $50 \%$ increased budget. The optimal policy mix can be observed from Figure 7. FIT is still at the minimum level. The most notable change is in spending for the installation subsidy for storage, which reaches very high levels, indicating a focus on storage diffusion, especially in the middle of the period. The other instruments remain relatively low. Compared to the runs with less budget, it seems that the budget constraint prevented investing more into storage, even though it would have been optimal. This indicates that, by large shares of the current budget being blocked by the 'old' FIT, a favorable shift in focus of the policy mix

\footnotetext{
${ }^{40}$ Note that there are no charts presented here since the developments are nearly linear. However, the results can be obtained on request.
} 
is impeded. This result again highlights the double-edged nature of the feed-in tariff. It allows the policy maker to induce strong diffusion and learning with little contemporary costs, but limits the choice set in the future.

Unsurprisingly, the higher budget allowed for better results. Diffusion reached 21\%, while $88 \%$ of all electricity generated was considered stable. Note that while the difference in stability appears to be small compared to the case with lower budget, it is actually much higher. If there is an increase in the diffusion of REGT, more unstable electricity is in the electricity market. Before, there were $19 \%$ of unstable electricity which had to be stabilised, now there are $21 \%$. Therefore, the actual amount of stabilised electricity was $4.5 \%$, while now it is $9 \%$. The number of storage facilities installed is therefore twice higher than before. However, even with the increased budget, the results both in stability and REGT diffusion are far away from their goals, indicating that more time is needed to reach them, especially for stability.

\subsection{Optimisation over the entire period $1990-2020$}

In contrast to Section 4.2 , the 30 year runs are not based on the 'history-friendly' part and therefore start in 1990. It is immediately observable from Figure 8 that FIT has much less dominance in the policy mix, which allows the policy maker to shift around budget freely. However, at the end of the time frame, there is a large investment into FIT, which is discussed below. The policy starts with a strong investment into basic R\&D for storage, which helps to make it available early on. After this, support for storage is mostly realised through installation subsidies (which is the policy instrument with the largest budget, except for FIT). Therefore, policy demonstrates demand-side focus only in the later period, while at the beginning a relatively larger emphasis is made on the supply-side support (R\&D).

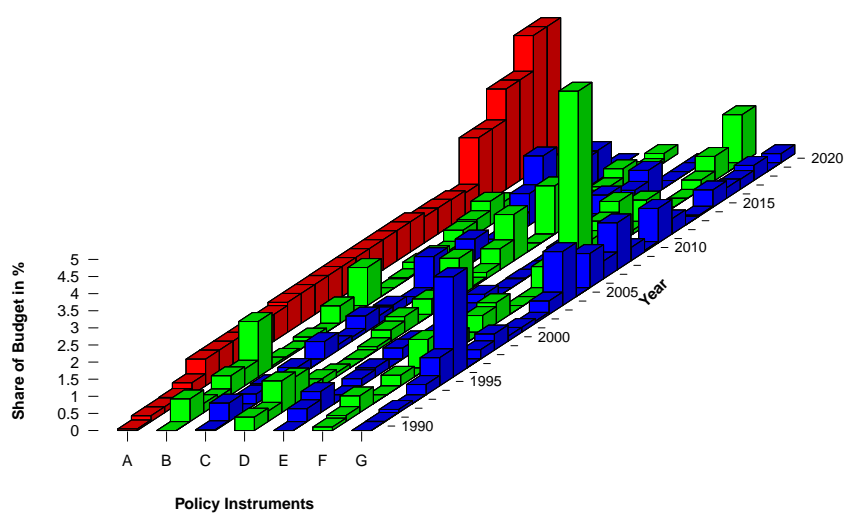

$\mathrm{A}=$ FIT for electricity from REGT

$\mathrm{B}=$ Public R\&D (REGT)

$\mathrm{C}=$ Public R\&D (Storage)

$\mathrm{D}=\mathrm{R} \& \mathrm{D}$ Subsidy (REGT)

$\mathrm{E}=\mathrm{R} \& \mathrm{D}$ Subsidy (Storage)

$\mathrm{F}=$ Installation Subsidy (REGT)

$\mathrm{G}=$ Installation Subsidy (Storage)

Figure 8: Policy Mix derived from 30 years DE runs

Figure 9 shows the development of several policy indicators over time. From the top left chart can be observed that the diffusion of REGT is weaker over a long time period compared to the actual German values. However, towards the end of the simulation there is a sudden rise in diffusion. In the end, 315 consumers did install REGT, which is more than in the previous outlook for ten years. The REGT price decreased by $75 \%$ over the 
time period, while the efficiency of the technology increased by 55\%. All in all, the system costs (price and efficiency combined) decreased by $85 \%$, which is not much more than what was achieved in the 'history-friendly' runs above. The reason for this finding is the learning effect becoming weaker with the number installations made. ${ }^{41}$
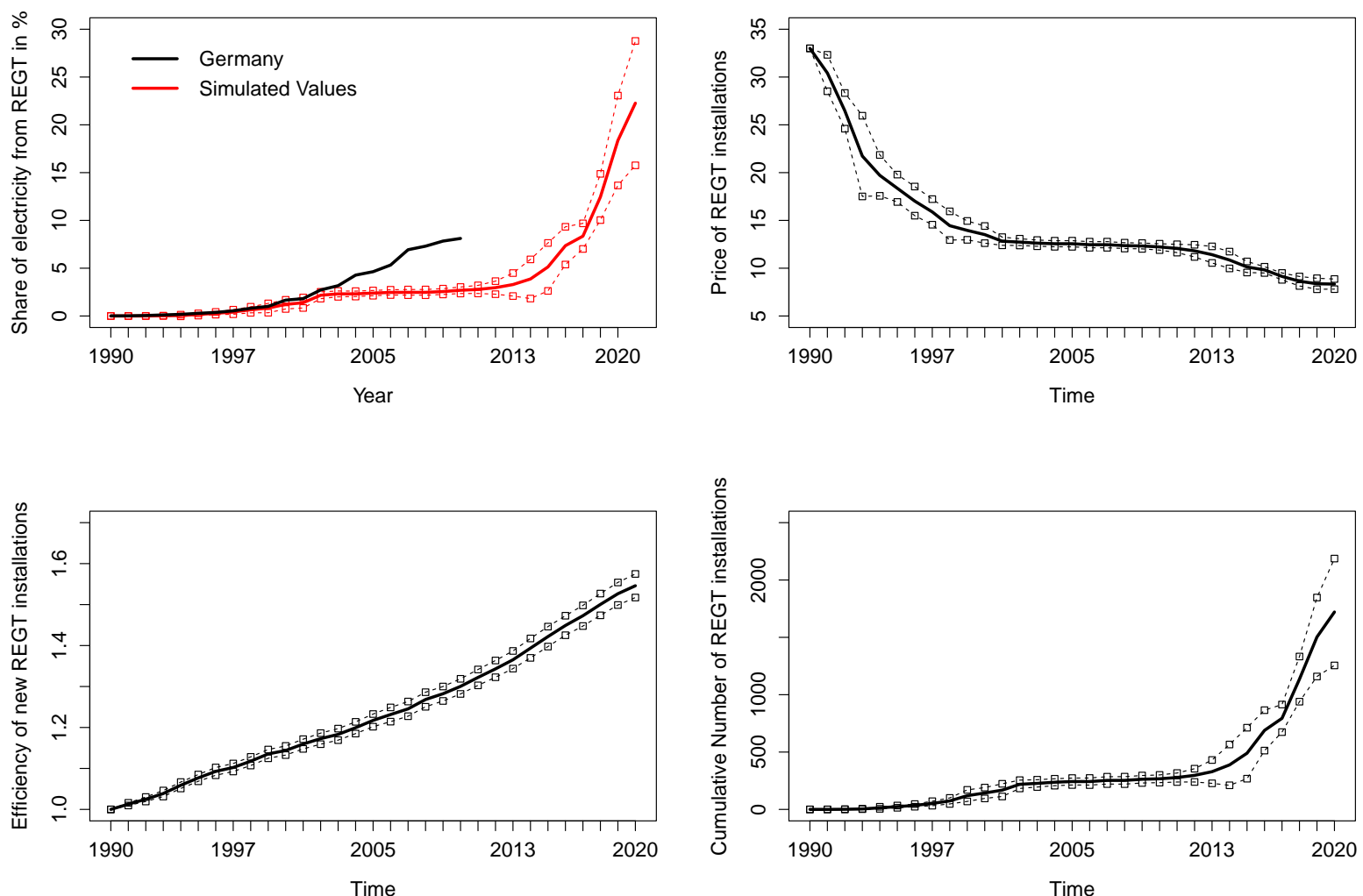

Figure 9: Characteristics of REGT evolution with optimal policy support

Note: In all charts the median run $+/$ - two standard deviations are presented.

The high final rate of diffusion can be attributed to the strong increase in FIT at the end and several periods of high installation subsidy for REGT. This seems to be an optimal solution since the strong demand-side support occurs in a period when the technology has already evolved for some time (based on R\&D), which increases the amount of REGT the government can support given the budget constraint. However, this strategy is only optimal since we take the diffusion at the end of the simulation as policy goal, while considering interim targets as well changes the result 42 Furthermore, even though the results are better than for the ten years run based on the 'history-friendly' results,

\footnotetext{
${ }^{41}$ Since we assume only a domestic market here, we do not consider the learning effect acquired elsewhere. We conducted tests including (exogenous) foreign demand with different strengths (i.e. allowing for up to 400 REGT plants being exported starting from year 2000 with increasing trend, to model a growing world market). The results are stable in terms of differences between the policy mixes and are available upon request.

${ }^{42} \mathrm{As}$ an alternative, we also tried to introduce an interim target for the REGT diffusion - the actual diffusion level of Germany in 2010. What one can observe is that because the policy maker is aware of the storage technology in advance and takes this into account while calculating optimal policy design, both more support and diffusion on the side of storage is observed. This comes at the price of lower budget and reached diffusion rates for REGT. The results are available on request.
} 
the actual policy goal of $26 \%$ diffusion is still not met. Here, the median result is $22.5 \%$ compared to $19 \%$ above.

The same can be said about storage technology. The share of stable electricity is much higher for the optimal policy mix over 30 years (89\%), compared to the ten years case. Again, since much more unstable electricity has to be stabilised compared to the original 10 years run, the amount of storage is much higher (11.5\% compared to $4.5 \%)$. As was the case for REGT, also for storage the diffusion is fastest towards the end of the observed period. 189 consumers did install storage facilities. In relation to the number of consumers who installed REGT, this is close to the result for the ten year runs, but here each consumer on average installed more storage facilities. Also, the number of people becoming autarkic from the grid is 20 for this run, which is 2.5 times more than in the counterfactual scenario with ten years and no budget increase (but still a low number). The price of storage facilities decreased by about $2 / 3$, while the efficiency increased by $30 \%$, which is still below the extent of REGT progress. This is not surprising, however, given that FIT supports Storage only indirectly.

2nd to 4th Income Decils

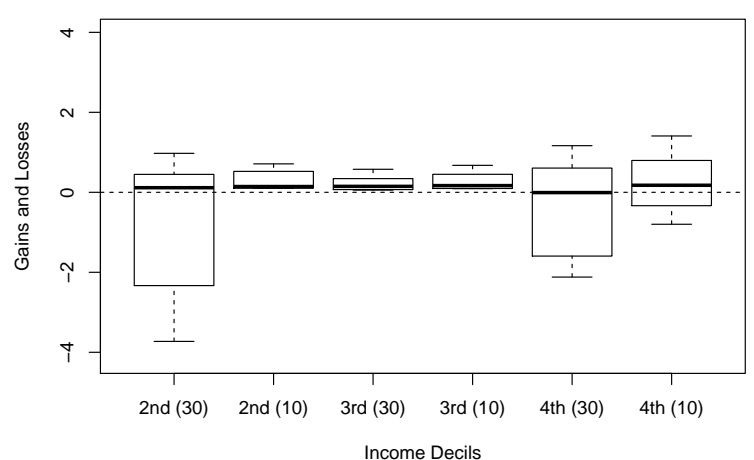

8th to 10th Income Decils

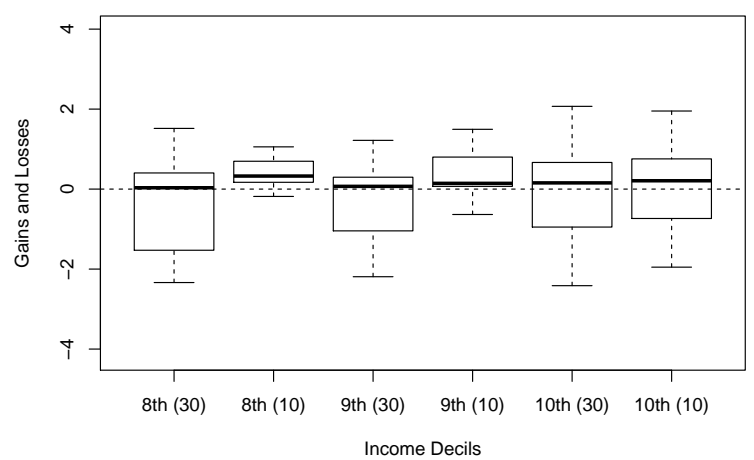

5th to 7th Income Decils

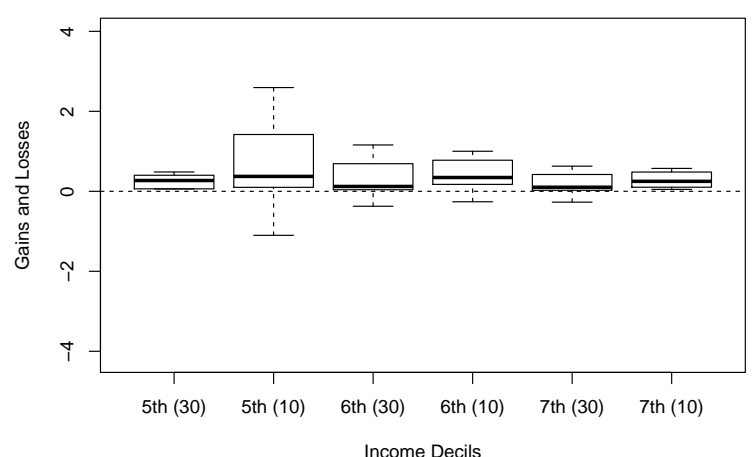

Number of Consumers with Installation in each Income Decile

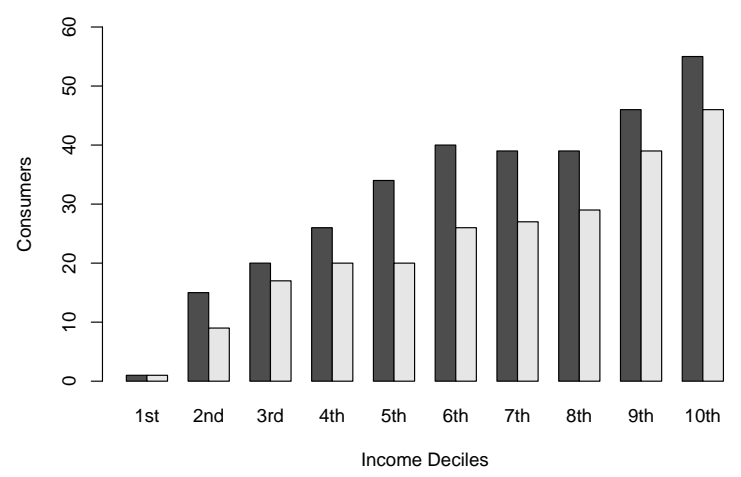

Figure 10: Gains and losses from investing into REGT for different policy mixes

Note: Gains and losses are in percent of income available. The first decile is not shown due to the too low number of consumers installing from this decile, which is illustrated in the bottom right chart - the number of people in both scenarios (dark gray with 30 years of DE optimization and light grey - the combination of 20 years of history-friendly policy mix and the last 10 years selected through DE optimization) investing in REGT grouped according to income deciles. The remaining deciles are shown in parallel for the case where DE was applied to the last ten years only (denoted with'(10)') and for the entire period 1990-2020 (denoted with'(30)').

Another interesting question is how much each policy mix crowds out the intrinsic incentives to install REGT based on preferences. Figure 10 illustrates the distribution of gains and losses among consumers who invested into REGT. In particular, it is clear 
that overall consumers benefit more when taking the history-friendly policy support as a basis. Hence, the policy mix derived from the 30 years DE experiment is better in two dimensions. First, it generates on average less gains for the consumers who installed REGT, which is good from the policy maker's perspective since those gains imply funds that could have been assigned more efficiently (i.e. policy support being 'wasted'; recall the quote from Cantono and Silverberg (2009) in the epigraph). Second, that policy mix has a higher number of consumers investing in REGT without FIT and installation subsidy. This means that in the absence of demand-side support the progress of the REGT and Storage technologies (thanks to supply side R\&D fostered by the policy mix) provoked consumers with high preferences to invest on their own, which is beneficial since the policy maker instead of crowding out private incentives involves consumers in sharing the cost of the transition process, and by this is able to produce superior results regarding the diffusion and stability. Note here that in the 30 years DE experiment there is also a relatively large number of consumers from the lower income percentiles who make losses, indicating that REGT reached the levelised cost that allows even relatively poor consumers to act upon their preferences.

The difference in installation pattern is further detailed in Figure 11. Here, it is depicted when each consumer made her REGT installation and how many plants were installed. In the upper graph (with first 20 years of a history-friendly scenario), one can see a lot of installations supported by FIT between 2000 and 2010, which is caused by the historically strong increase in FIT during this period. As a side consequence, there are quite few installations afterward (none of them supported by FIT). In the lower graph, there are much less installations prior to 2015. Instead, one observes many small installations (majority being done without any demand-side support). Once FIT is increased, a very strong investment (especially from wealthier consumers) takes place. It is worth stressing here that given the REGT technology is more advanced in this scenario by 2015, those FIT and installation subsidy measures cost much less in absolute values to secure a large number of installations.

\section{Discussion and Conclusion}

This study models development of the electricity market in Germany over the period between 1990-2010 and makes an outlook for the following ten years. Its aim is to analyse the conditions under which a transition towards a sustainable electricity can be achieved more efficiently. The transition is based on diffusion of two different technologies: the renewable electricity generation and storage. Since both are characterised by high costs and low efficiency at the beginning, policy intervention is necessary to start the transition (as it is shown in the simulations run without policy support in Section 3). Without policy intervention, the diffusion process stops very fast, since there are too few consumers investing at the current prices and efficiency levels to make the technology an attractive investment to the broader mass of people.

Using a set of policy interventions sharing important features of the policy mix applied in Germany over the last 20 years, we are able to reproduce a very similar diffusion pattern as observed in Germany in 1990-2010. We take this result as a basis for our counterfactual exercise, in which we aim to optimise the policy mix reaching simultaneously high REGT diffusion and high (electricity grid's) stability for the following ten years. From the history-friendly experiments we can gain several insights. First of all, the introduction of 


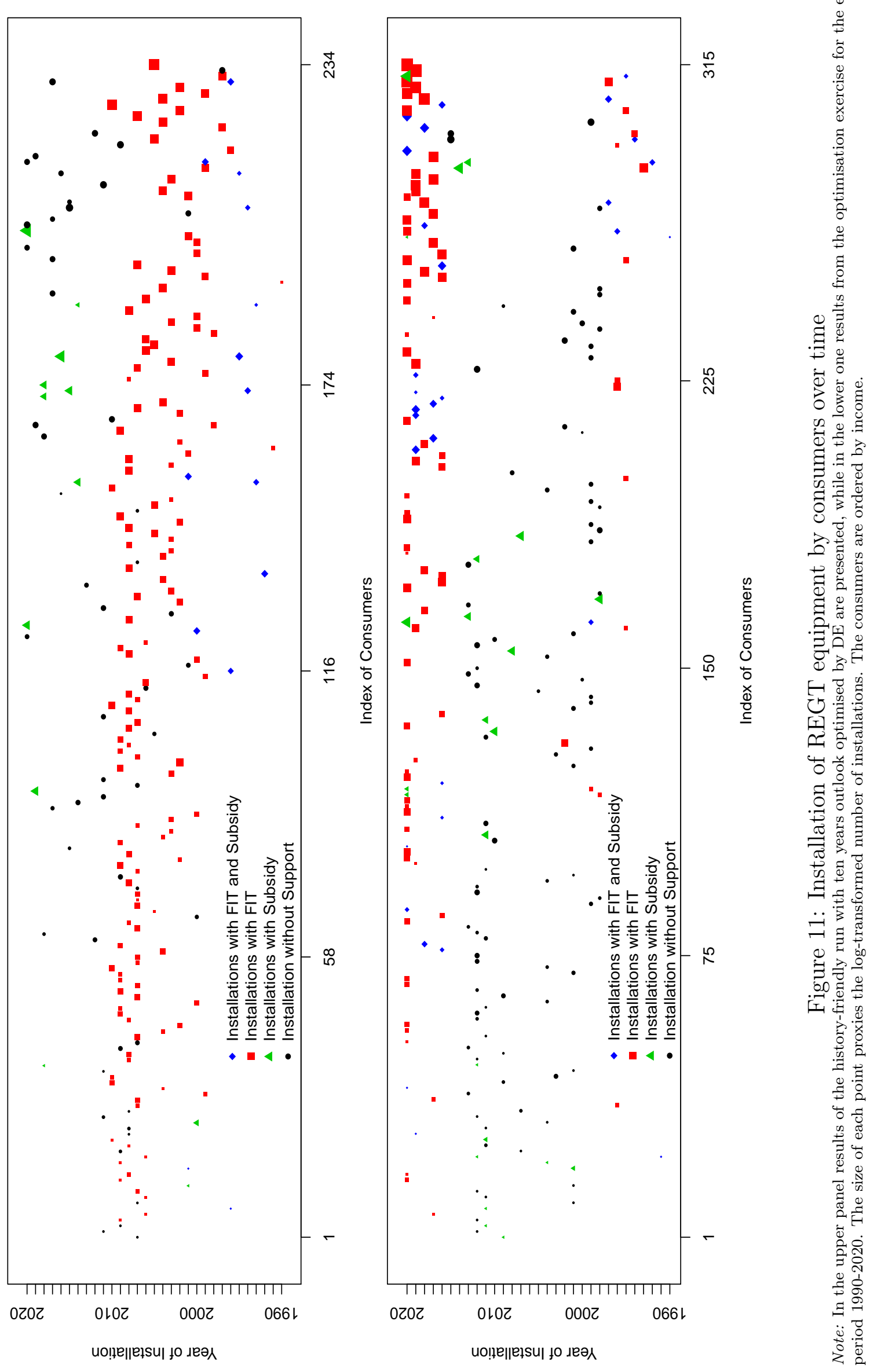


FIT is a very effective and contemporary cheap way of inducing the diffusion of REGT. However, this comes at relatively high costs later on and is inflexible over time. In particular, since FIT is granted for 20 years, it is not possible to reduce spending on FIT in the short run, at least not without breaking the promise given by policy maker to respective households. Introducing FIT creates strong path dependency inside the policy mix, as future spending has to take into account the funds already promised for FIT in former periods. In addition, FIT (and to some extent also REGT installation subsidies) is crowding out voluntary investment into REGT installations, since even people who would invest without incentives are better off accepting FIT or the subsidy (or both).

The counterfactual analysis, in its turn, demonstrates the possibility to identify a policy mix over 1990-2020 by DE which is superior to the one for 2010-2020 based on the results of the 'history-friendly' run. This indicates that, for the purpose of reaching the 2020 target of REGT diffusion, the historical policy mix of Germany introduced too strong demand-side instruments too early. While they did produce impressive diffusion rates, it would have been more cost efficient to introduce them later, when the technology was more evolved and the same amount of money could have generated more diffusion. Of course, this is at odds with the goal to bring greenhouse emissions down as fast a possible, since most greenhouse gases accumulate over time in the atmosphere, which makes an early diffusion desirable. Also, from an international perspective, it creates interesting and adverse incentives. If one assumes that imitation of a technology is cheap (or if the technology can be bought by the cheapest producer without restrictions), each country has an incentive to postpone own investment into REGT and storage technology as long as possible, to benefit from the improvements based on the investments made by others. This is likely to lead to an underinvestment in the technology and a too low rate of diffusion to tackle the international climate problems.

To sum up, the following policy insights can be gained. First of all, it is important to define binding intermediate goals, to ensure a steady diffusion of new technologies and to avoid adverse incentives. In addition, the policy maker should avoid fixing large shares of its budget over a long period of time, since it looses the ability to react to changes in the development (e.g., the emergence of a new technology). To avoid a conflict between the two objectives, a policy mix regarding the long-term diffusion of a new technology should be based on as broad as possible political consensus. Otherwise, a government fearing to loose an election against competitors, who follow different policy goals regarding the technology, might be tempted to create precedents by using policy instruments that bind the policy maker over a long period of time to 'conserve' its political will in this field.

In none of our (median) scenarios the policy makers were able to fulfill the goals they set themselves for 2020. This can have several reasons. One possible explanation is that we prohibited budget increases after the 'history-friendly' period, assuming that the policy maker wants to avoid further cost increases, which could jeopardise the political support for REGT from the electorate. Even with a $50 \%$ increased budget, the policy maker is not able to meet its goal, though the results improve. Another option we have excluded consists in the possibility of breaking the promise to buy REGT electricity at the fixed price through FIT (e.g., in 2011 just after the history-friendly period). The modeling of a such a policy shock, however, is not trivial, while we consider this option to be rather unrealistic. Last but not least, one could model interaction with foreign markets in more detail and increase their importance. In particular, while some robustness tests allowing manufacturers to export some REGT and Storage plants did not change the results considerably, one could consider the possibility of exogenous technological im- 
provements in the form of knowledge spillovers or import of superior plants from other global technological leaders such as the USA and Japan. On the other hand, one should remember that we took the evolution of the fossil fuel price from 2011 onwards as a random walk which seems to be clearly above the price dynamics we observe today (and can be considered as an unexpected economic shock). Since the lower fossil fuel price makes the fossil electricity more competitive, one would need even stronger support for the transition process, which in its turn makes the realisation of the 2020 policy goal even less likely.

There are several promising directions to extend our work. One limitation of our model as of now is that preferences are fixed, which is not very realistic given the long time period under consideration. Therefore, a preference changing mechanism, e.g. due to consumer interaction, would add some explanatory power, especially if the 'eco-warriors' are able to convince other consumers. Also, we make the assumption that all consumers interact with each other with the same probability, which is again unlikely. Therefore, a spatial representation of consumers would contribute to our model. Ideally this should be implemented through a certain network structure, in which single consumers are only connected to a limited number of other consumers. However, this would increase the computational demand of our model greatly. A more suitable option would be to introduce a regional structure, where each consumer is assigned to a specific region. Consumers who belong to the same region have a higher chance of interacting with each other. Also, this would allow us to study the effect of REGT on the electricity grid better, since one could assume that certain transmission capacity is necessary to transfer electricity between the regions, which is interesting because the irradiation and wind power being unevenly distributed inside most countries. This should allow one to look at regional effects of REGT and storage technology as well.

\section{References}

Arthur, W. (2006). Out-of-equilibrium economics and agent-based modeling. In l. Tesfatsion and Judd, K., editors, Handbook of Computational Economics. Agent-Based Computational Economics, chapter 32, pages 1551-1584. Elsevier, North-Holland.

Battiston, S., Farmer, J. D., Flache, A., Garlaschelli, D., Haldane, A. G., Heesterbeek, H., Hommes, C., Jaeger, C., May, R., and Scheffer, M. (2016). Complexity theory and financial regulation. Science, 351(6275):818-819.

Bleda, M. and Valente, M. (2009). Graded eco-labels: A demand-oriented approach to reduce pollution. Technological Forecasting \& Social Change, 76(4):512-524.

Blueschke, D., Blueschke-Nikolaeva, V., and Savin, I. (2013). New insights into optimal control of nonlinear dynamic econometric models: Application of a heuristic approach. Journal of Economic Dynamics and Control, 37(4):821-837.

Blueschke-Nikolaeva, V., Blueschke, D., and Neck, R. (2012). Optimal control of nonlinear dynamic econometric models: An algorithm and an application. Computational Statistics and Data Analysis, 56(11):3230-3240.

Bode, S. and Groscurth, H.-M. (2006). The effect of the German renewable energy act (EEG) on 'the electricity price'. Technical Report 358, HWWA Discussion Paper. 
Candelisea, C., Winskelb, M., and Grossa, R. J. K. (2013). The dynamics of solar pv costs and prices as a challenge for technology forecasting. Renewable and Sustainable Energy Reviews, 26:96-107.

Cantner, U., Graf, H., Herrmann, J., and Kalthaus, M. (forthcoming). Inventor networks in renewable energies: The influence of the policy mix in Germany. Research Policy.

Cantono, S. and Silverberg, G. (2009). A percolation model of eco-innovation diffusion: the relationship between diffusion, learning economies and subsidies. Technological Forecasting \& Social Change, 76(4):487-496.

Colmenar-Santos, A., Campinez-Romero, S., Perez-Molina, C., and Castro-Gil, M. (2012). Profitability analysis of grid-connected photovoltaic facilities for household electricity self-sufficiency. Energy Policy, 51:749-764.

De Grauwe, P. (2011). Animal spirits and monetary policy. Economic Theory, 47:423457.

del Río, P. and Bleda, M. (2012). Comparing the innovation effects of support schemes for renewable electricity technologies: A function of innovation approach. Energy Policy, 50:272-282.

Department of Energy \& Climate Change, U. (2013). Annual Report on Fuel Poverty Statistics 2013, UK. Available at https://www.gov.uk/government/uploads/ system/uploads/attachment_data/file/199833/Fuel_Poverty_Report_2013_ FINALv2.pdf

Destatis (2015). Genesis Online Database, Erzeugerpreisindizes gewerblicher Produkte, GP09-061: Erdöl. Available at https://www-genesis.destatis.de/genesis/ online.

Diaz-Rainey, I. and Ashton, J. K. (2011). Profiling potential green electricity tariff adopters: green consumerism as an environmental policy tool? Business Strategy and the Environment, 20(7):456-470.

Divya, K. and Østergaard, J. (2009). Battery energy storage technology for power systems - an overview. Electric Power Systems Research, 79.

EASE/EERA (2013). Recommendations for a European energy storage technologydevelopment roadmap towards 2030. Available at http://www.ease-storage.eu/ launch-ease-eera-energy-storage-technology-development-roadmap-towards-2030-new . html.

Faber, M. and Proops, J. L. R. (1991). The innovation of techniques and the time-horizon: A neo-Austrian approach. Structural Change and Economic Dynamics, 2(1):143-158.

Fagiolo, G. and Roventini, A. (2012). Macroeconomic policy in dsge and agent-based models. Revue de l'OFCE, 124(5):67-116.

Farhoodnea, M., Mohamed, A., Shareef, H., and Zayandehroodi, H. (2013). Power quality impact of renewable energy based generators and electric vehicles on distribution systems. Procedia Technology, 4th International Conference on Electrical Engineering and Informatics, ICEEI 2013, 11:11-17. 
Garavaglia, C. (2010). Modelling industrial dynamics with "history-friendly" simulations. Structural Change and Economic Dynamics, 21(4):258-275.

German Council of Economic Experts (2009). Jahresgutachten 2009/10 - "Die Zukunft nicht aufs Spiel setzen" (in German). Available at http://www .sachverstaendigenrat-wirtschaft.de/fileadmin/dateiablage/ download/gutachten/ga09_ges.pdf

German Federal Government (2010). Energiekonzept für eine umweltschonende, zuverlässige und bezahlbare energieversorgung (in German). Available at http://www.bundesregierung.de/ContentArchiv/DE/Archiv17/_Anlagen/ 2012/02/energiekonzept-final.pdf.

German Federal Minstry for the Environment, N. C. and Nuclear Safety (2012). Development of renewable energy sources in Germany in 2011 - Based on statistical data from the Working Group on Renewable Energy-Statistics (AGEEStat). Available at http://www.bmub.bund.de/fileadmin/bmu-import/files/ english/pdf/application/pdf/ee_in_deutschland_graf_tab_en.pdf.

Gilli, M. and Schumann, E. (2014). Optimization cultures. Wiley Interdisciplinary Reviews: Computational Statistics, 6(5):352-358.

Grau, T., Huo, M., and Neuhoff, K. (2012). Survey of photovoltaic industry and policy in Germany and China. Energy Policy, 51:20-37.

Guerci, E., Rastegar, M., and S.Cincotti (2010). Agent-based modeling and simulation of competitive wholesale electricity markets. In Handbook of Power Systems II, pages 241-286. Springer, Berlin, Heidelberg.

Hadjipaschalis, I., Poullikkas, A., and Efthimiou, V. (2009). Overview of current and future energy storage technologies for electric power applications. Renewable and Sustainable Energy Reviews, 13(1513-1522).

Jacobsson, S. and Lauber, V. (2006). The politics and policy of energy system transformation - explaining the German diffusion of renewable energy technology. Energy Policy, 34(3):256-276.

JRC - European Commission (2015). Global irradiation and solar electricity potential in Germany. Available at http://www.zonu.com/detail-en/2011-05-24-13743/ Global-irradiation-and-solar-electricity-potential-in-Germany.html.

Lantz, E., Wiser, R., Hand, M., Arapogianni, A., Cena, A., Simonet, E., and JamesSmith, E. (2012). IEA wind task 26: The past and future cost of wind energy work package 2. Technical report, National Renewable Energy Laboratory of the U.S. Department of Energy.

Lauber, V. and Mez, L. (2004). Three decades of renewable electricity policies in Germany. Energy \& Environment, 15(4):599-623.

Lehr, U. and Drosdowski, T. (2013). Soziale Verteilungswirkungen der EEG-Umlage. Discussion Paper 3, gws Discussion Paper. 
Lindman, A. and Söderholm, P. (2012). Wind power learning rates: A conceptual review and meta-analysis. Energy Economics, 34(3):754-761.

Liu, W., Lund, H., and Mathiesen, B. V. (2011). Large-scale integration of wind power into the existing chinese energy system. Energy, 36(8):4753-4760.

Lopolito, A., Morone, P., and Taylor, R. (2013). Emerging innovation niches: An agent based model. Research Policy, 42(6-7):1225-1238.

Malerba, F., Nelson, R., Orsenigo, L., and Winter, S. (2008). Public policies and changing boundaries of firms in a 'history-friendly' model of the co-evolution of the computer and semiconductor industries. Journal of Economic Behavior \& Organization, 67:355-380.

Mishra, A., Irwin, D., Shenoy, P.and Kurose, J., and Zhu, T. (2012). Smartcharge: Cutting the electricity bill in smart homes with energy storage. In Proceedings of the 3rd International Conference on Future Energy Systems: Where Energy, Computing and Communication Meet, e-Energy '12, New York, NY, USA. ACM.

Nannen, V. and van den Bergh, J. (2010). Policy instruments for evolution of bounded rationality: Application to climate-energy problems. Technological Forecasting \& Social Change, 77:76-93.

Rifkin, J. (2011). The Third Industrial Revolution: How Lateral Power Is Transforming Energy, the Economy, and the World. Palgrave MacMillan.

Ringler, P., Keles, D., and Fichtner, W. (2016). Agent-based modelling and simulation of smart electricity grids and markets - a literature review. Renewable and Sustainable Energy Reviews, 57:205-215.

Roe, B., Teisi, M., Levy, A., and Russell, M. (2001). US consumers' willingness to pay for green electricity. Energy Policy, 29(11):917-925.

Rogge, K. S. and Reichardt, K. (2015). Going beyond instrument interactions: Towards a more comprehensive policy mix conceptualization for environmental technological change. SPRU Working Paper Series (SWPS) 2015-12.

Safarzynska, K., Frenken, K., and van den Bergh, J. (2012). Evolutionary theorizing and modeling of sustainability transitions. Research Policy, 41(6):1011-1024.

Safarzynska, K. and van den Bergh, J. (2013). An evolutionary model of energy transitions with interactive innovation-selection dynamics. Journal of Evolutionary Economics, 23:271-293.

Savin, I. and Blueschke, D. (2015). Lost in translation: Explicitly solving nonlinear stochastic optimal control problems using the median objective value. Computational Economics, forthcoming.

Sensfuß, F., Genoese, M., Ragwitz, M., and Möst, D. (2007). Agent-based simulation of electricity markets - a literature review. Energy Studies Review, 15(2).

Sensfuß, F., Ragwitz, M., and Genoese, M. (2008). The merit-order effect: A detailed analysis of the price effect of renewable electricity generation on spot market prices in Germany. Energy Policy, 36(8):3086-3094. 
Steffen, B. (2012). Prospects for pumped-hydro storage in Germany. Energy Policy, 45:420-429.

Steinmueller, W. (2013). The pre-industrial energy crisis and resource scarcity as a source of transition. Research Policy, 42(10):1739-1748.

Storn, R. and Price, K. (1997). Differential evolution: a simple and efficient adaptive scheme for global optimization over continuous spaces. J. Global Optimization, 11:341359 .

Stubenrauch, F. (2003). National survey report of PV power applications in Germany 2002. Technical report, German Federal Ministry of Economy and Technology.

Tesfatsion, L. and Judd, L., editors (2006). Handbook of Computational Economics, Volume II: Agent-Based Computational Economics. North-Holland.

van der Zwaan, B. (2003). Prospects for PV: a learning curve analysis. Solar Energy, 74(1):19-31.

Weidlich, A. and Veit, D. (2008). A critical survey of agent-based wholesale electricity market models. Energy Economics, 30(4):1728-1759.

Williams, C. (2013). Electric avenue. New Scientist, 218(2922):38-41.

Windrum, P., Chiarli, T., and Birchenhall, C. (2009). Consumer heterogeneity and the development of environmentally friendly technologies. Technological Forecasting \& Social Change, 76:533-551.

Wiser, R. (2007). Using contingent valuation to explore willingness to pay for renewable energy: A comparison of collective and voluntary payment vehicles. Ecological Economics, 62(3-4):419-432.

Wissing, L. (2013). National survey report of PV power applications in Germany. Technical report, International Energy Agency.

Zahedi, A. (2006). Solar photovoltaic (PV) energy: latest developments in the building integrated and hybrid PV systems. Renewable Energy, 31:711-718. 


\section{Appendices}

\section{A Analytical description of the simulation model}

Table 1: Parameters used

\begin{tabular}{|c|c|c|c|}
\hline & Description & Symbol & Value \\
\hline \multirow{12}{*}{ 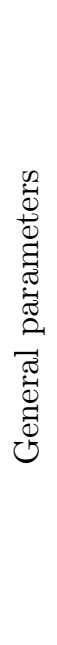 } & Number of consumers & $N$ & 1000 \\
\hline & Share of 'eco-warriors' & $\delta$ & 0.05 \\
\hline & Number of fossil producers & $P$ & 10 \\
\hline & Number of manufacturers & $M$ & 3 \\
\hline & Number of periods considered by manufacturers for capacity change & $S$ & 5 \\
\hline & Maximum production capacity increase per period & Inc & 1 \\
\hline & Maximum production capacity decrease per period & $D e c$ & 0.5 \\
\hline & Average percentage of GDP per year government support & & \\
\hline & in history-friendly run (240 periods) & Support & 0.75 \\
\hline & Average percentage of GDP per year government support & & \\
\hline & in DE (120 Periods) & Support $_{D} E$ & 1.53 \\
\hline & $\begin{array}{l}\text { Average percentage of GDP per year government support } \\
\text { in DE ( } 360 \text { Periods) }\end{array}$ & Support $_{D} E$ & 0.95 \\
\hline \multirow{6}{*}{ 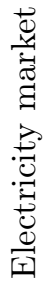 } & Life expectation of fossil power plants (years) & $\operatorname{Life}_{f}$ & 40 \\
\hline & Life expectation of REGT (years) & Life $e_{r}$ & 20 \\
\hline & Life expectation of storage technology (years) & Lifes & 20 \\
\hline & Maximum percentage of income to be spent on electricity & $\phi$ & 0.1 \\
\hline & Minimal up-time of fossil plants & $\gamma$ & 0.7 \\
\hline & Initial value for fuel price & FuelPrice $_{t}$ & 1 \\
\hline \multirow{12}{*}{ 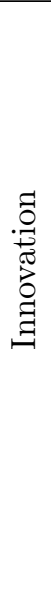 } & Parameter for learning effects & LearnRate & 0.86 \\
\hline & Share of manufacturer's turnover invested into R\&D & share $R D$ & $5 \%$ \\
\hline & Initial value for number of sold REGT installations & StockSold ${ }_{r, t}$ & 3 \\
\hline & Initial value for number of sold storage installations & StockSold $_{s, t}$ & 3 \\
\hline & Initial value for number of sold fossil plants & StockSold $_{f, t}$ & 250 \\
\hline & Initial value for installation cost of REGT & InstallCost $_{r, t}$ & 32 \\
\hline & Initial value for installation cost of storage technology & InstallCost $_{s, t}$ & 32 \\
\hline & Initial value for installation cost of fossil plants & InstallCost $_{f, t}$ & 200 \\
\hline & Initial value for efficiency of REGT & Efficiency $_{r, t}$ & 1 \\
\hline & Initial value for efficiency of storage technology & Efficiency $_{s, t}$ & 1 \\
\hline & Initial value for efficiency of fossil technology & Efficiency $_{f, t}$ & 105 \\
\hline & Foreign Demand for REGT (Standard) & ForeignDemand $r, t$ & 0 \\
\hline
\end{tabular}




\section{B On initial conditions used and results obtained}
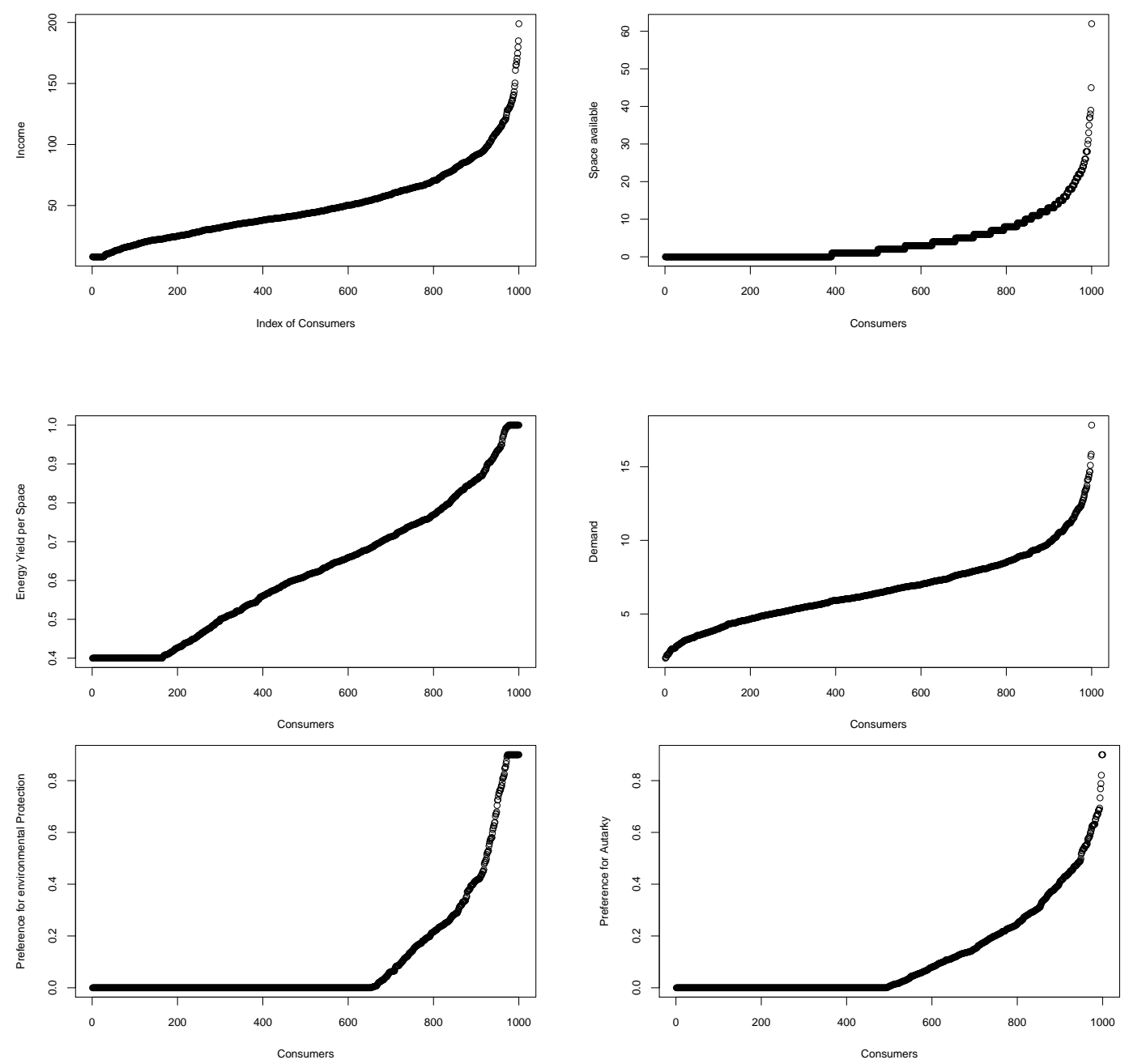

Figure 12: Income, space, irradiation, demand distributions and preferences (for REGT and storage technologies) of consumers

Note: On the $\mathrm{x}$-axis consumers are always ordered in ascending order for the corresponding variable on the y-axis. Hence, consumers with, e.g., highest income are not the ones with highest preference for REGT.
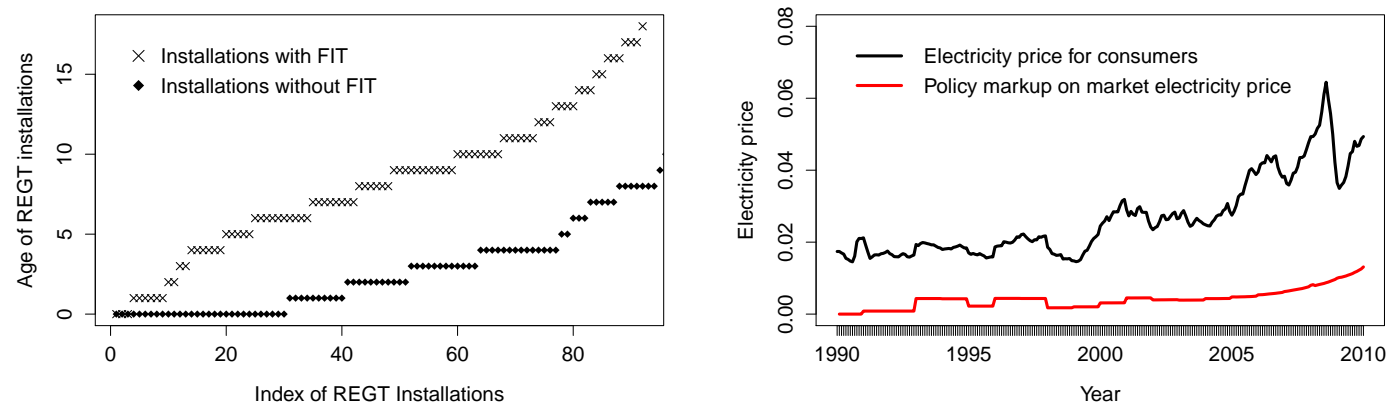

Figure 13: Characteristics of new REGT installations and electricity price 

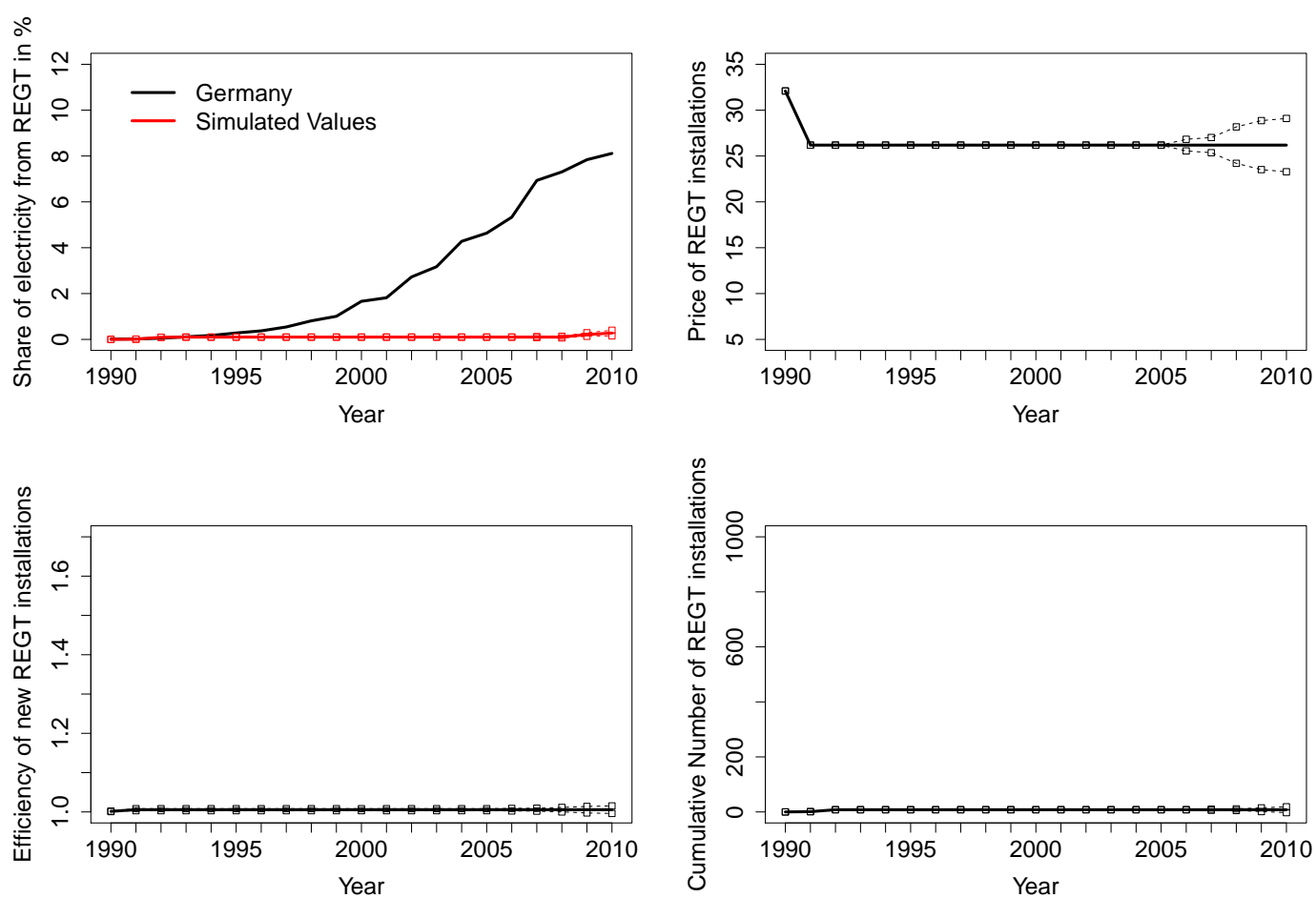

Figure 14: Characteristics of REGT evolution without policy support Note: In all charts the median run $+/$ - two standard deviations are presented.

\section{Robustness tests}

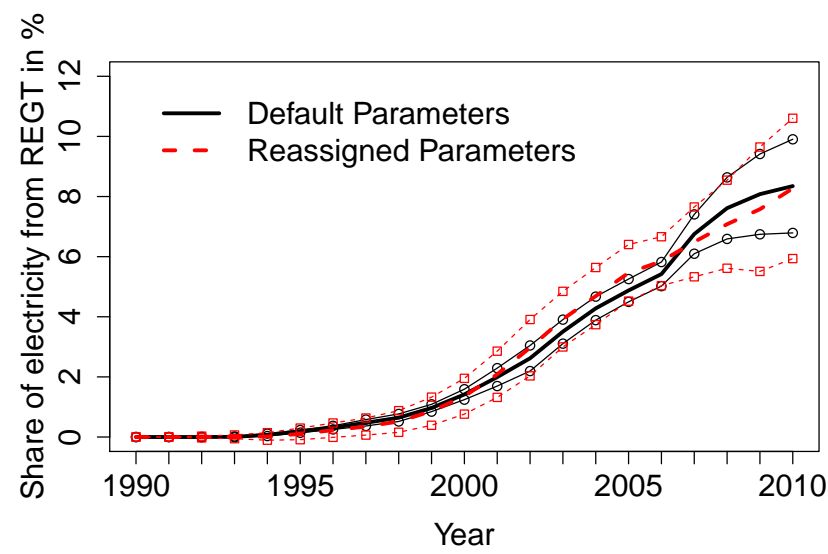

Figure 15: Effect of reassigning consumer parameters each run

Note: For both parameter distribution scenarios the median run $+/-$ two standard deviations are presented. 

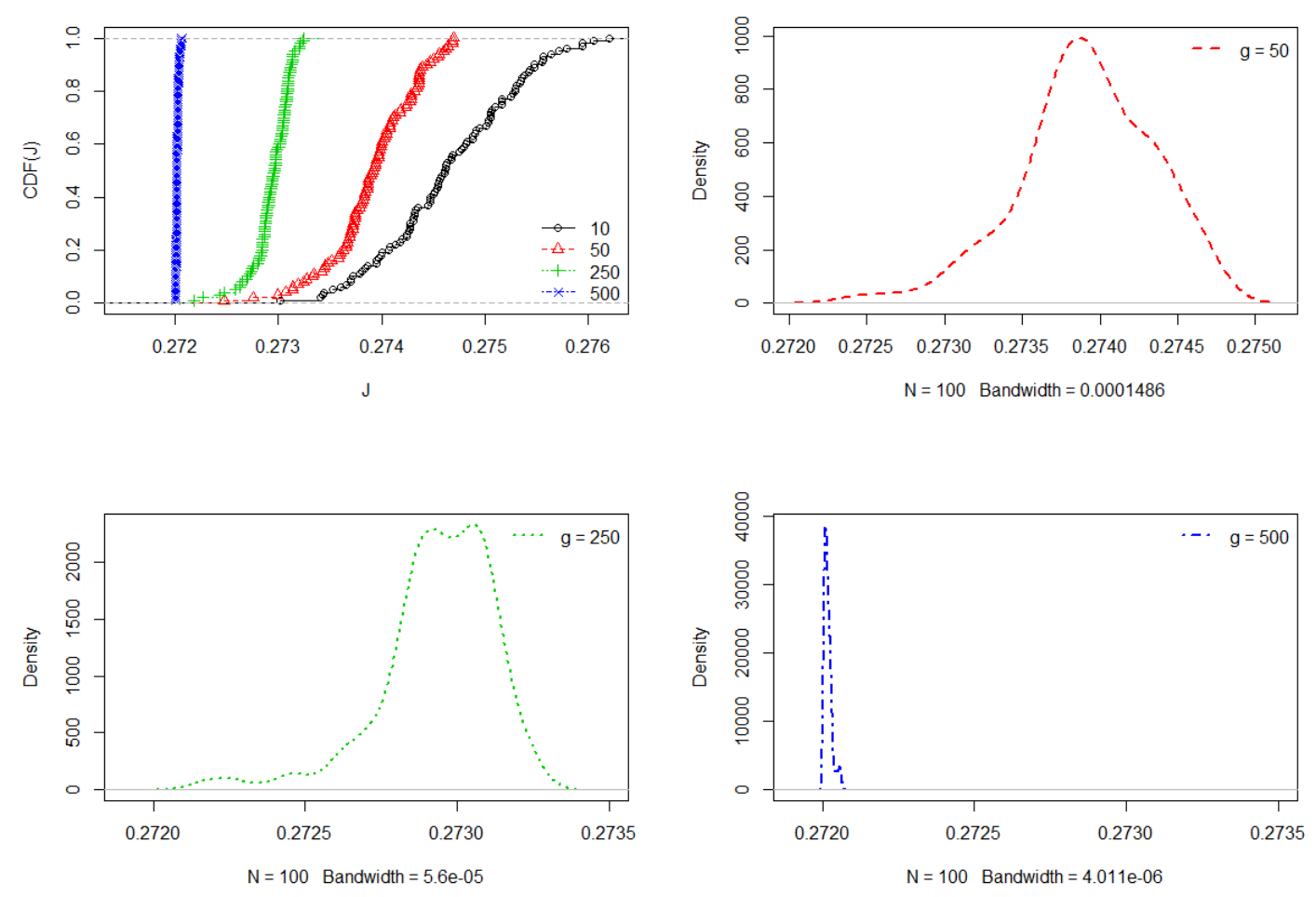

Figure 16: Empirical distribution of objective function values for different $g$ 


\section{Working Paper Series in Economics}

recent issues

No. 87 Johannes Karl Herrmann and Ivan Savin: Optimal policy Identification: Insights from the German electricity market, March 2016

No. 86 Andranik Tangian: Devaluation of one's labor in labor-commoditiesmoney-commodities-labor exchange as a cause of inequality growth, February 2016

No. 85 Thomas Deckers, Armin Falk, Fabian Kosse and Nora Szech: Homo moralis: Personal characteristics, institutions, and moral decision-making, February 2016

No. 84 Markus Fels: When the affordable has no value, and the valuable is unaffordable: The U.S. market for long-term care insurance and the role of Medicaid, February 2016

No. 83 Uwe Cantner, Ivan Savin, Simone Vannuccini: Replicator dynamics in value chains: Explaining some puzzles of market selection, February 2016

No. 82 Helena Barnard, Robin Cowan, Moritz Müller: On the value of foreign PhDs in the developing world: Training versus selection effects, January 2016

No. 81 Enno Mammen, Christoph Rothe, Melanie Schienle: Semiparametric estimation with generated covariates, January 2016

No. 80 Carsten Bormann, Julia Schaumburg, Melanie Schienle: Beyond dimension two: A test for higher-order tail risk, January 2016

No. 79 Frank Betz, Nikolaus Hautsch, Tuomas A. Peltonen, Melanie Schienle: Systemic risk spillovers in the European banking and sovereign network, January 2016

No. 78 Armin Falk and Nora Szech: Pleasures of skill and moral conduct, January 2016

No. 77 Kirill Borissov, Mikhail Pakhnin, Clemens Puppe: On discounting and voting in a simple growth model, December 2015 